\title{
Temporal Masking Reveals Properties of Sound-Evoked Inhibition in Duration-Tuned Neurons of the Inferior Colliculus
}

\author{
Paul A. Faure, Thane Fremouw, John H. Casseday, and Ellen Covey \\ Department of Psychology, University of Washington, Seattle, Washington 98195-1525
}

The inferior colliculus (IC) is the first place in the central auditory pathway where duration-selective neurons are found. Previous neuropharmacological and electrophysiological studies have shown that they are created there and have led to a conceptual model in which excitatory and inhibitory inputs are offset in time so that the cell fires only when sound duration is such that onset- and offsetevoked excitation coincide; the response is suppressed by inhibition at other durations. We tested predictions from the model using paired tone stimulation and extracellular recording in the IC of the big brown bat, Eptesicus fuscus. Responses to a best duration (BD) tone were used as a probe to examine the strength and time course of inhibition activated by a nonexcitatory (NE) tone of the same frequency but differing in duration. As the relative time between the BD and NE tones was varied, the activity evoked by the BD tone was affected in ways comparable with backward, simultaneous, and forward masking. Responses to the BD tone were completely suppressed at short interstimulus intervals when the BD tone preceded the NE tone. Suppression was also seen when the stimuli temporally overlapped and summed and at intervals when the BD tone followed the NE tone. The results show that duration-selective neurons receive an onsetevoked, inhibitory input that precedes their excitatory input. The period of leading inhibition was correlated with BD and first spike latency. The results suggest how inhibition in the CNS could explain temporal masking phenomena, including backward masking.

Key words: audition; auditory midbrain; big brown bat (Eptesicus fuscus); duration tuning; echolocation; neural delay lines; neuroethology

\section{Introduction}

Temporal features of sound convey information vital for behaviors as diverse as speech recognition by humans and echolocation by bats (Popper and Fay, 1995; Shannon et al., 1995). One simple but important temporal attribute is signal duration. For example, bats emit ultrasonic vocalizations and listen to the reflected echoes to determine the distance and other properties of objects in their environment (Simmons and Stein, 1980). The time between vocalization and echo varies with object distance. Most bats precisely adjust their signal duration to avoid temporal overlap between the outgoing call and the returning echo (Griffin, 1958; Kalko and Schnitzler, 1989). For this process to work, the CNS must somehow represent signal duration. In the inferior colliculus (IC) of bats and other mammals, this representation is achieved by neurons tuned to signal duration, with different cells having different best durations (BDs) (Casseday et al., 1994; Ehrlich et al., 1997; Fuzessery and Hall, 1999; Brand et al., 2000). Duration-tuned neurons have also been described in the mammalian visual cortex (Duysens et al., 1996), suggesting that duration selectivity is a general feature of sensory processing.

\footnotetext{
Received 0ct. 22, 2002; revised Jan. 9, 2003; accepted Jan 17, 2003.

This work was supported by National Institutes of Health Research Grants DC-00287 and DC-00607 and Research Core Center Grant DC-04661 from the National Institute on Deafness and Other Communication Disorders. We thank Appalachia Martine and Kimberly Miller for technical assistance, Brandon Warren for expert programming, and two anonymous reviewers whose critical comments greatly improved this manuscript.

Correspondence should be addressed to Paul A. Faure, Department of Psychology, University of Washington, Box 351525 Guthrie Hall, Seattle, WA 98195-1525. E-mail: paul4@u.washington.edu.

T. Fremouw's present address: Department of Psychology, University of California at Berkeley, Tolman Hall, Berkeley, CA 94720-1650.

Copyright $\odot 2003$ Society for Neuroscience $\quad 0270-6474 / 03 / 233052-14 \$ 15.00 / 0$
}

Neuropharmacological experiments and intracellular recordings indicate that duration tuning is created in the IC (Casseday et al., 1994, 2000; Covey et al., 1996). A conceptual model has been proposed to show how duration selectivity could be formed through interaction of excitatory and inhibitory events offset in time (Fig. 1). The model has three components, each of which probably represents the summed effect of multiple synaptic inputs to the cell: (1) transient, onset-evoked EPSP; (2) sustained, onset-evoked IPSP with a latency shorter than or equal to the EPSP latency; and (3) transient, offset-evoked excitation, possibly attributable to rebound from the sustained inhibition.

The cell fires action potentials whenever sound duration is such that two excitatory events ( 1 and 3 above) coincide. It fails to respond when the sound is so short that the rebound from inhibition is over before the onset-evoked EPSP arrives or when it is so long that the sustained inhibition overrides the onset-evoked EPSP. The BD of the cell, range of duration selectivity, and duration filter characteristic are controlled by the latency and duration of the onset-evoked EPSP (Fig. 1).

In the present study, we used extracellular recording and stimulation with tone pairs to measure the strength and time course of the proposed inhibition. We presented a probe tone at the $\mathrm{BD}$ of a cell and a test tone of the same frequency but at a nonexcitatory (NE) duration. Changing the temporal relationship between the two produced effects on the excitatory responses to the $\mathrm{BD}$ tone that allowed us to quantify the time course of the presumed synaptic inhibition evoked by the NE tone. Our results provide information on the latency, duration, and decay of the onsetevoked inhibition, as well as information on how the time course of inhibition determines the $\mathrm{BD}$, first spike latency, and duration 


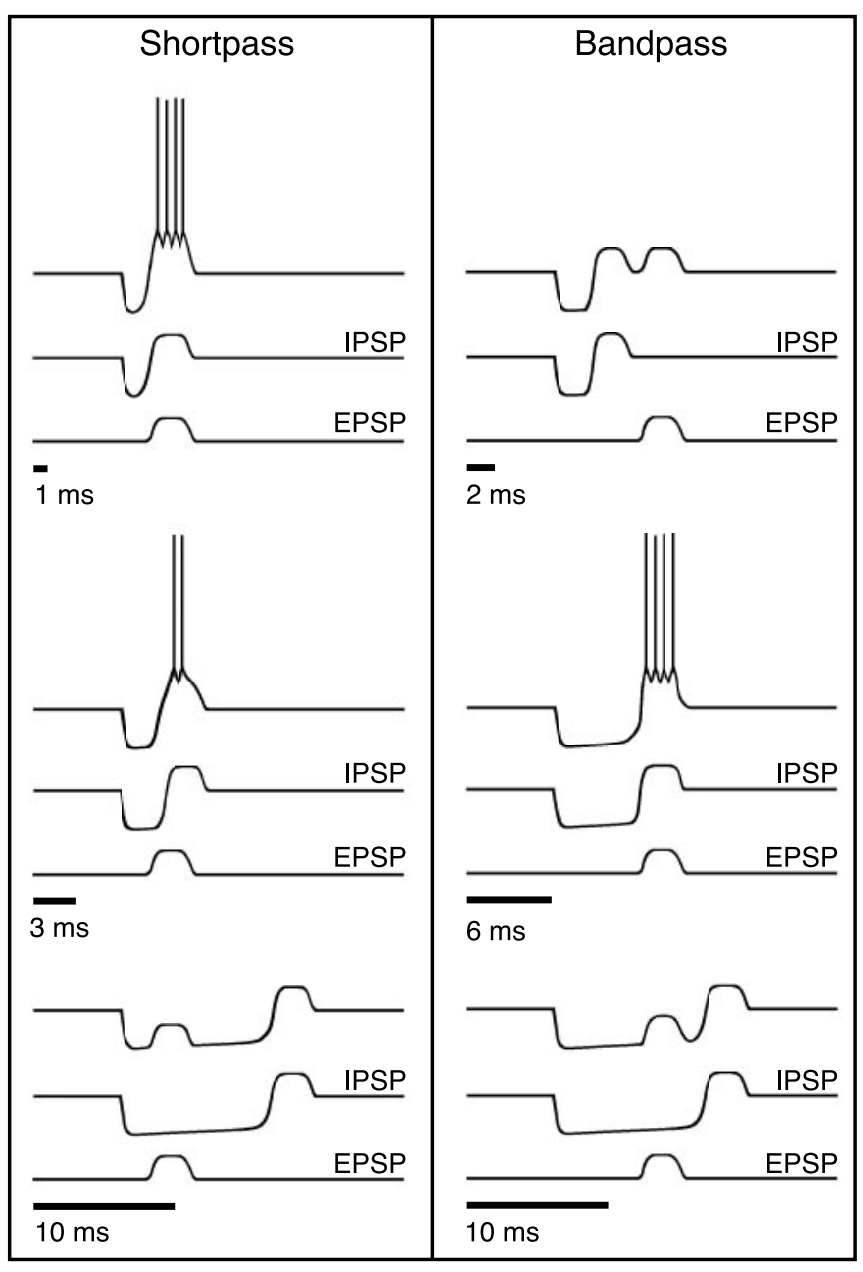

Figure 1. Model for the creation of short-pass and bandpass duration tuning. Above each stimulus (black bars), three traces are shown. The middle and bottom traces represent hypothetical synaptic inputs to an IC neuron; the top traces show the resulting change in the membrane potential of the cell and, if suprathreshold, its spike output. The model has three components: (1) transient, onset-evoked, subthreshold EPSP (bottom traces); (2) sustained, onset-evoked, IPSP; and (3) a following transient, excitatory rebound from inhibition (middle traces). Neurons fire only when the EPSP coincides with the excitatory rebound from the IPSP. The best duration and range of duration selectivity of a cell are determined by the duration of the EPSP and its latency relative to the IPSP. Shortpass, For the 1 msec tone, the EPSP coincides with the rebound from inhibition, and the summation pushes the membrane potential of the cell above the spike threshold. For the 3 msec tone, the EPSP is partially cancelled by the IPSP, resulting in a weaker suprathreshold response and a longer first spike latency. For the $10 \mathrm{msec}$ tone, the EPSP occurs before the end of the IPSP and is rendered subthreshold by the sustained inhibition. Bandpass, For the $2 \mathrm{msec}$ tone, the rebound from inhibition occurs before the EPSP. For the $6 \mathrm{msec}$ tone, the rebound from inhibition coincides with the EPSP, and the summation pushes the membrane potential of the cell above spike threshold. For the 10 msec tone, the EPSP occurs before the end of the IPSP and is rendered subthreshold by the sustained inhibition. Modified from Casseday et al. (2002).

filter characteristic of duration-tuned neurons. The neurophysiological results were analogous to the phenomena of backward, simultaneous, and forward masking in psychophysics.

\section{Materials and Methods}

\section{Surgical procedures}

Neural recordings were obtained from 25 big brown bats (Eptesicus fuscus) of both sexes. To prepare a bat for electrophysiological recording, a small stainless steel post was attached to the skull. The bat was anesthetized by a combination of Metofane (methoxyflurane) inhalation (1-5 $\mathrm{min}$ ) and subcutaneous injection of a neuroleptic [0.3 $\mathrm{ml} \mathrm{1:1} \mathrm{mixture} \mathrm{of}$ $0.025 \mathrm{mg} / \mathrm{ml}$ fentanyl citrate and $1.25 \mathrm{mg} / \mathrm{ml}$ Inapsine (droperidol); 19.1 $\mathrm{mg} / \mathrm{kg}]$. The animal was then placed in a foam-lined restraint molded to the shape of the body to hold it firmly but comfortably yet still allowing access to the head. The head was immobilized by placing the animal in a bite bar attached to manipulators that allowed the head to be placed in a standard position. The hair overlying the skull was cropped, and the skin was swabbed with Betadine surgical scrub. Local anesthetic $(0.05 \mathrm{ml}$ of $2 \%$ lidocaine) was administered before making a midline incision in the scalp. The temporal muscles were reflected, and the skull was scraped clean of tissue and then swabbed with $100 \%$ ethanol. The post was glued to the skull overlying the dorsal surface of the cortex using cyanoacrylate gel adhesive (Zap Gel; Pacer Technology) and liquid acrylic hardener (Jet Liquid; Lang Dental Manufacturing Co.). A chlorided silver wire was placed under the temporal musculature to serve as the reference electrode. Recording began 1-4 d after surgery. Each bat was used in one to six recording sessions lasting $\sim 6 \mathrm{hr} / \mathrm{d}$. Experiments were terminated if the bat showed any signs of discomfort. Between sessions, the wound was covered with Gelfoam coated with Neosporin. Bats were housed in individual cages in a temperature- and humidity-controlled environment and were given ad libitum access to food and water. All procedures were approved by the University of Washington Laboratory Animal Care and Use Committee.

\section{Acoustic stimuli}

Sound pulses were digitally synthesized with two digital signalprocessing boards from Tucker Davis Technologies (TDT; Apos II sampling rate, $357 \mathrm{kHz}$ ) optically interfaced to TDT hardware modules, including two digital-to-analog (D/A) converters (TDT DA3-2). The output of each D/A converter was fed through a low-pass antialiasing filter [TDT FT5; filter cutoff frequency $\left(f_{\mathrm{c}}\right), 120 \mathrm{kHz}$ ] and two programmable attenuators (TDT PA4). The two outputs were then mixed by a weighted summer (TDT SM5) and fed to an attenuator (Leader LAT-45) before final amplification (Krohn-Hite 7500). All stimuli were presented monaurally, contralateral to the recording IC from a Brüel \& Kjær (B\&K) Type $4135^{1 / 4}$ inch condenser microphone (protective grid on) modified for use as a loudspeaker with a circuit to correct for nonlinearities in the transfer function (Frederiksen, 1977). The transducer was positioned so that its diaphragm was $\sim 1 \mathrm{~mm}$ in front of the external auditory meatus. The output of the loudspeaker, measured with a B\&K Type 4138 and 1/8 inch condenser microphone (diaphragm, $90^{\circ}$ incidence; protective grid off) calibrated with a B\&K Type 4220 sound level calibrator, is expressed in decibels of sound pressure level (SPL root mean square with regard to $20 \mu \mathrm{Pa}$ ) equivalent to the peak amplitude of continuous tones of the same frequency (Stapells et al., 1982). The transfer function of the transducer was flat $\pm 5 \mathrm{~dB}$ from 26 to $118 \mathrm{kHz}$. Over the range of frequencies used in this study, the SPL at the ear opposite the source was at least $30 \mathrm{~dB}$ below the level of the source (Ehrlich et al., 1997). All signals had rise-fall times of $0.4 \mathrm{msec}$ shaped with a square cosine function. Stimuli were presented at a repetition rate of 3 pulses/sec.

\section{Neurophysiology}

Electrophysiological recordings were conducted in a double-walled, sound-attenuating chamber (Industrial Acoustics Co., Inc.). Before recording, each bat was given a subcutaneous injection of neuroleptic (see Surgical procedures). Bats were then placed in a foam-lined body restraint that was suspended in an elastic sling within a stereotaxic frame (ASI Instruments) mounted atop a floating vibration table (TMC Microg). The head of the bat was immobilized by attaching the distal end of the head post to a customized holder mounted on a stereotaxic micromanipulator (David Kopf Instruments). The post holder prevented the bat from moving its head during recording and allowed for the precise repositioning of the head between recording sessions. A small opening was made in the skull and in the dura mater overlying the IC for insertion of the recording electrode. Single-unit extracellular recordings were obtained with thin-wall borosilicate glass microelectrodes (outer diameter, $1.2 \mathrm{~mm}$; A-M Systems, Inc.) filled with $0.3-0.5 \mathrm{M} \mathrm{NaCl}$. The mean $\pm \mathrm{SD}$ electrode resistance was $20.6 \pm 7.7 \mathrm{M} \Omega(n=72)$. Electrodes were visually aimed at the IC, which in bats extends to the dorsal surface of the brain and is visible through the skull. Electrodes were advanced with a stepping hydraulic micropositioner (David Kopf Instruments model 650). Action 
potentials were recorded with a Neuroprobe amplifier (A-M Systems model 1600), the $10 \times$ output of which was further amplified and bandpass-filtered (TDT PC1; low-pass $f_{\mathcal{c}}, 700 \mathrm{~Hz}$; high-pass $f_{\mathcal{c}}, 3 \mathrm{kHz}$ ) before passing through a spike discriminator (TDT SD1). Spike times were logged on a computer by feeding the output of the spike discriminator into an event timer (TDT ET1) synchronized to a timing generator (TDT TG6). Stimulus generation and on-line data visualization were controlled with custom software. Spike times were displayed as dot rasters ordered by the acoustic parameter that was randomized during testing. Peristimulus rastergrams were produced with Igor Pro software (WaveMetrics, Inc.).

\section{Data collection}

Testing for duration selectivity. Our study specifically focused on the physiology of duration-selective cells. No attempt was made to systematically sample the IC to determine the relative proportion of duration-tuned cells, which has previously been reported as being approximately onethird of IC units in E. fuscus (Ehrlich et al., 1997). Search stimuli were pure tones and frequency-modulated (FM) sweeps. Whenever a cell was isolated, it was tested for duration selectivity by presenting it with suprathreshold pure tone pulses that were varied in duration. If the responses of a cell appeared to be selective for signal duration, the cell was subjected to further testing.

Three tests were conducted on all cells that showed duration selectivity: (1) The approximate frequency tuning of the cell was audiovisually determined at a stimulus duration that evoked strong suprathreshold spiking. (2) The minimum threshold and best excitatory frequency (BEF) of the cell were obtained by an automated procedure. Blocks of pure tone pulses (same duration as in 1) spanning the bandwidth determined in 1 were presented in $10 \mathrm{~dB}$ steps above threshold. Frequency was randomly varied within the block, and 10-15 stimulus repetitions were presented at each frequency step. The data were used to construct a visual representation of the frequency response area consisting of poststimulus time histograms for every frequency and SPL combination. (3) The BD of the cell was measured by presenting blocks of BEF tone pulses that were randomly varied in duration. Blocks were in $10 \mathrm{~dB}$ steps above threshold, with 10-20 stimulus presentations at each duration step. The usual range of test durations was $1-25$ msec.

Criteria for duration tuning. Duration filter characteristics were determined using responses evoked by a BEF tone at $10 \mathrm{~dB}$ above threshold (in one case, $20 \mathrm{~dB}$ ). A cell was classified as bandpass duration-tuned if the spike counts at durations both longer and shorter than BD were $\leq 50 \%$ of the spike count at BD. A cell was classified as short-pass duration-tuned if the spike count at durations longer than $\mathrm{BD}$ was $\leq 50 \%$ of the spike count at BD. We did not obtain data from neurons that were selective for an FM stimulus, because the responses of these cells are determined by an interaction between the rate of frequency change and stimulus duration, and they respond poorly, if at all, to pure tones.

Testing with tone pairs. We recorded extracellular responses while stimulating with pairs of pure tones that differed in their duration and temporal relationship (Fig. $2 \mathrm{~A}$ ). One tone in the pulse pair was set at the $\mathrm{BD}$ of the cell (BD tone); the other tone was set at a duration that was nonexcitatory (NE tone). The two tones were identical in frequency and were set at the BEF of the cell. The BD and NE tones were initially presented at equal amplitude, typically at $10 \mathrm{~dB}$ above the $\mathrm{BD}$ tone threshold. The onset time of the NE tone was designated as time $=0$. The presentation time of the $\mathrm{BD}$ tone was randomly varied relative to that of the NE tone. The range of presentation times for the roving $\mathrm{BD}$ tone was chosen so that neural responses occurred over some range of times when the $\mathrm{BD}$ tone both preceded and followed the NE tone. Typically, the presentation time of the $\mathrm{BD}$ tone was varied in $2 \mathrm{msec}$ steps, with $10-20$ responses collected at each step. For a subset of cells, we also varied the duration of the NE tone and the amplitude of the $\mathrm{BD}$ tone relative to that of the NE tone. Because the BD and NE tones were the same frequency, whenever they summed at different positions of temporal overlap, the result was a single composite tone with an amplitude modulation, the duration of which was determined by the duration of the BD tone and by the amount of stimulus overlap. Because the BD and NE tones were not phase-matched, at some positions of temporal overlap, the modulation
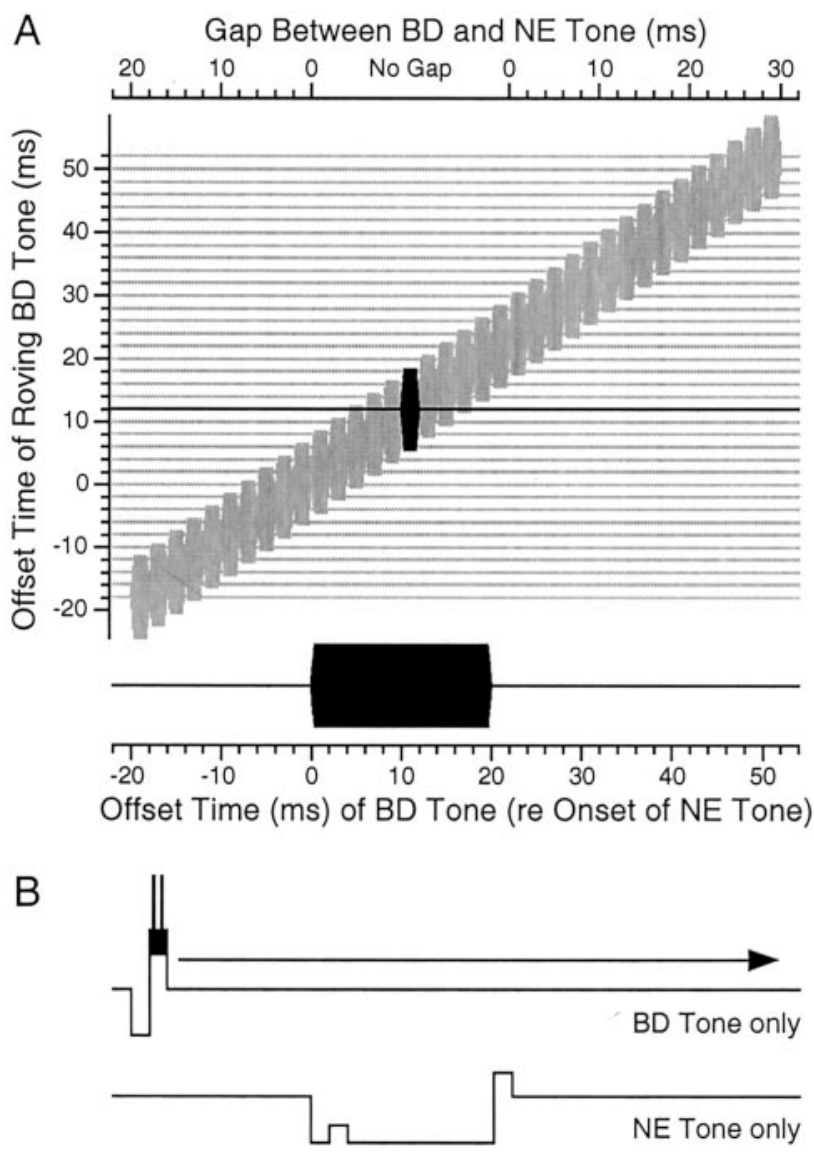

Figure 2. Paired tone testing of duration-tuned neurons. $A$, Schematic illustrating the stimulus paradigm. The onset time of the NE tone (20 msec black pulse) was fixed from one stimulus presentation to the next. The presentation time of the BD tone (2 msec black pulse) was randomly varied ( gray pulses) relative to the onset of the NE tone. When the two tones temporally overlapped and summed, the result was a single composite tone with an amplitude modulation. Top $x$-axis, Interstimulus interval. Bottom $x$-axis, Offset time of the BD tone with regard to onset time of the NE tone. $y$-Axis, Offset time of the BD tone with regard to onset time of the NE tone. In this and similar figures, negative times indicate that the offset of the $B D$ tone preceded the onset of the NE tone, whereas at positive times, it followed the onset of the NE tone. B, Time course of hypothetical changes in the membrane potential of a duration-tuned neuron in response to a $2 \mathrm{msec} \mathrm{BD}$ tone alone (top trace) or a $20 \mathrm{msec} \mathrm{NE}$ tone alone (bottom trace). As the BD tone is moved to different temporal positions with regard to onset of the NE tone (black arrow), interaction between the two would be expected to result in spike suppression when the EPSP at the offset of the BD tone overlaps with the IPSP evoked by the onset of the NE tone. Thus, the response of the cell to the $B D$ tone serves as a probe to measure the strength and time course of the inhibition evoked by the NE tone. The sequences of excitatory and inhibitory changes in membrane potential are derived from Figure 1. Membrane potentials are illustrated as square waves to emphasize the temporal sequence of IPSP and EPSP inputs and do not reflect the actual amplitudes or the time constants of the subthreshold potentials, which would vary between neurons and across stimulus conditions. The black portion of the BD Tone only trace indicates the suprathreshold portion of the summed EPSP and rebound from inhibition.

was an amplitude decrement. We were interested in neural responses to amplitude increments in the composite stimulus; therefore, data points obtained at different positions of temporal overlap were included in our analysis if, and only if, summation of the BD and NE tones resulted in a composite stimulus with an amplitude increment (i.e., a pedestal) that was within $3 \mathrm{~dB}$ of the maximum theoretical amplitude increase that was expected to result from the summation of phase-matched tones of the same amplitude ratio.

\section{Data analysis}

Measuring the strength and time course of inhibition. We used the response of a neuron to the $\mathrm{BD}$ tone as a probe to measure properties of the inhibition evoked by the NE tone (Fig. $2 B$ ). Spike counts and first and 


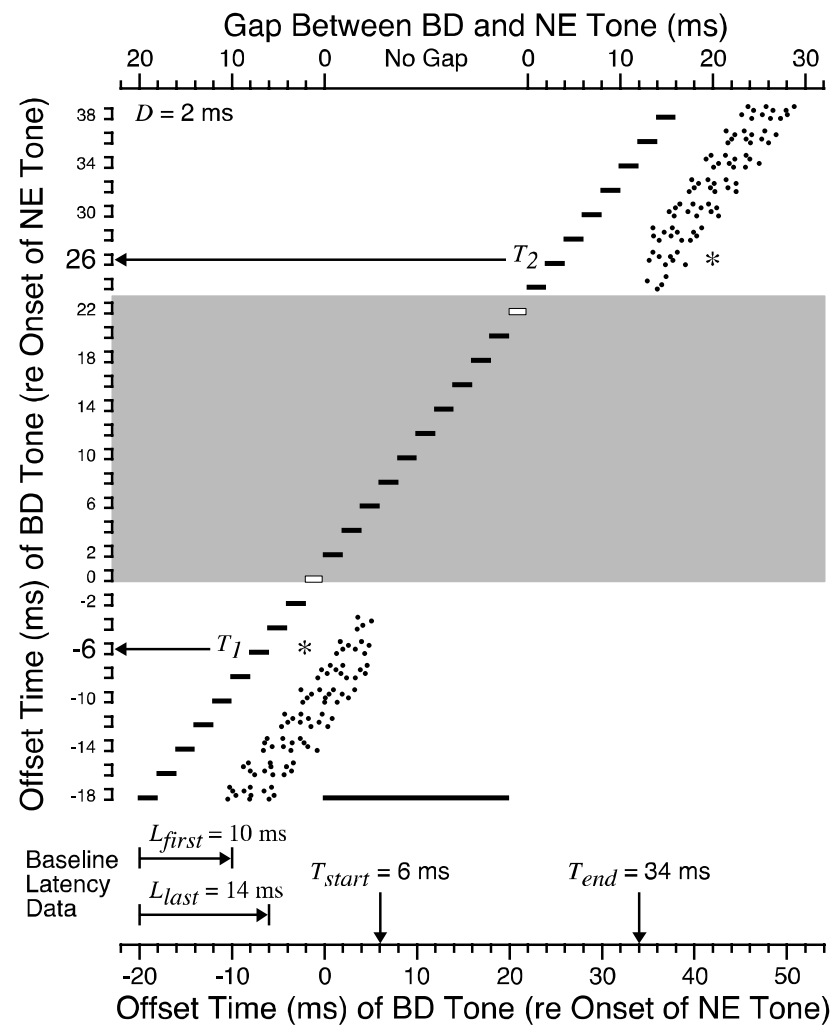

$$
\begin{aligned}
& T_{\text {start }}=T_{1}+L_{\text {last }}-D \\
& T_{\text {end }}=T_{2}+L_{\text {first }}-D
\end{aligned}
$$

Figure 3. Measuring inhibition with paired tone stimulation. The schematic peristimulus rastergram (stacked dot display) shows how changes in the timing and number of action potentials (black dots) can be used to calculate the effective start $\left(T_{\text {start }}\right)$ and end $\left(T_{\text {end }}\right)$ times of the inhibition evoked by the NE tone with the equations at the bottom. For this hypothetical cell, the average baseline first spike latency $\left(L_{\text {first }}\right)$ is $10 \mathrm{msec}$, and the average baseline last spike latency $\left(L_{\text {last }}\right)$ is $14 \mathrm{msec}$. The first time interval at which the mean last spike latency of the cell decreased by $>1 \mathrm{SD}$ below $L_{\text {last }}$ was $T_{1}=-6 \mathrm{msec}$ (asterisk). The last time interval at which the mean first spike latency of the cell remained $>1 S D$ above $L_{\text {first }}$ was $T_{2}=26 \mathrm{msec}$ (asterisk). The $B D$ and NE tones are illustrated as black bars. BD bars with a white fill indicate two time intervals when the $B D$ tone was contiguous with, but did not overlap, the NE tone. The gray box indicates the range of times over which the BD tone was contiguous with or overlapped the BD tone to form a single composite stimulus with an amplitude increment (i.e., a pedestal). $B D$ tone duration, $D=2 \mathrm{msec}$; NE tone duration, $20 \mathrm{msec}$.

last spike latency measurements were used to assess the effective strength and time course of the inhibition. The average number of spikes per stimulus and the average first and last spike latencies were calculated off-line using custom software with an analysis window. The start and stop times of the analysis window, which were anchored to the onset and offset of the probe tone, were chosen to accommodate the latency and spike burst duration of each cell and to minimize the effects of spontaneous activity, if present.

The time course of the inhibition evoked by the NE tone was quantified by constructing plots showing mean spike count and mean first and last spike latency as a function of the relative time between the offset of the $\mathrm{BD}$ tone and the onset of the NE tone. First, each plot was inspected to determine the time point at which the mean spike count of the cell in response to the $\mathrm{BD}$ tone began to decrease. Data from times before this decrease, when the $\mathrm{BD}$ tone preceded the NE tone and the two signals were well separated in time, were used to calculate the average baseline number of spikes per stimulus of the cell \pm 1 average SD and average baseline first and last spike latencies \pm 1 average SD.

Figure 3 illustrates the method of computing the time course of the inhibition evoked by the NE tone. The effective start time of the inhibition $\left(T_{\text {start }}\right)$ relative to the onset of the NE tone was calculated as:

$$
T_{\text {start }}=T_{1}+L_{\text {last }}-D,
$$

where $T_{1}$ is the first time interval at which the mean last spike latency of the cell decreased by $>1$ SD from baseline; $L_{\text {last }}$ is the baseline last spike latency of the cell (with regard to onset of BD tone); and $D$ is the duration of the BD tone. For the hypothetical data in Figure 3, the first time interval at which the mean last spike latency of the cell decreased by $>1$ $\mathrm{SD}$ from baseline was when the offset of the BD tone preceded the onset of the NE tone by $6 \mathrm{msec}\left(T_{1}=-6 \mathrm{msec}\right)$. By adding $T_{1}$ to the baseline last spike latency of the cell $\left(L_{\text {last }}=14 \mathrm{msec}\right)$, minus the duration of the BD tone $(D=2 \mathrm{msec})$, the start time of the inhibition and hence its latency were calculated to occur $6 \mathrm{msec}$ after the onset of the NE tone.

The effective end time of the inhibition $\left(T_{\text {end }}\right)$ relative to the onset of the NE tone was calculated as:

$$
T_{\text {end }}=T_{2}+L_{\text {first }}-D \text {, }
$$

where $T_{2}$ is the last time interval at which the mean first spike latency of the cell in response to the $\mathrm{BD}$ tone was $>1$ SD from baseline; $L_{\text {first }}$ is the baseline first spike latency of the cell (with regard to onset of $\mathrm{BD}$ tone); and $D$ is the duration of the BD tone. For the hypothetical data in Figure 3 , the last time interval at which the mean first spike latency of the cell was $>1$ SD from baseline was when the offset of the BD tone followed the onset of the NE tone by $26 \mathrm{msec}\left(T_{2}=26 \mathrm{msec}\right)$. By adding $T_{2}$ to the baseline first spike latency of the cell $\left(L_{\text {first }}=10 \mathrm{msec}\right)$, minus the duration of the BD tone $(D=2 \mathrm{msec})$, the stop time of the inhibition was calculated to occur $34 \mathrm{msec}$ after the onset of the NE tone.

The total duration of the inhibition evoked by the NE tone was calculated as $T_{\text {end }}-T_{\text {start }}$. A neuron was said to have leading inhibition if the latency of the inhibition was less than the excitatory first spike latency. A neuron was said to have persistent inhibition if the total duration of the inhibition was greater than the duration of the NE tone (Bauer et al., 2000).

For cases in which cells responded with only a single spike (i.e., first spike latency = last spike latency), instances in which the spike count of the cell was clearly suppressed even though the mean last or first spike latencies remained within $1 \mathrm{SD}$ of baseline, or both, $T_{1}$ was the first time interval at which the spike count of the cell decreased to $\leq 50 \%$ of baseline, and likewise, $T_{2}$ was the last time interval at which the spike count of the cell remained $\leq 50 \%$ of baseline. A spike count criterion was used to measure $T_{1}$ in 55 of 255 data files (22\%; data from 20 neurons). In all but one case, the baseline response of the cell was one spike per stimulus. A spike count criterion was used to measure $T_{2}$ in 65 of 255 data files $(26 \%$; data from 25 neurons). In 42 of the cases, the baseline response of the cell was one spike per stimulus. In the remaining 23 files, a spike count criterion was also used, because, although the first spike latency of the cell had recovered, its spike count was still strongly suppressed; therefore, this criterion more accurately reflected the time course of the inhibition. In cases in which the mean first spike latency of a cell had not returned to within 1 SD of baseline within the range of presentation times tested $(n=$ 4 files), $T_{2}$ was conservatively estimated as the largest time interval that was tested.

To verify that the spike count and latency criteria yielded equivalent results for single spiking neurons, we analyzed 40 data files from 16 cells in which both criteria could be applied. The average differences between the two measures (latency criterion minus spike count criterion) were $-0.5 \pm 1.3 \mathrm{msec}$ for $T_{1}$ and $2.0 \pm 4.7 \mathrm{msec}$ for $T_{2}$. The differences are at or within the measurement resolution $(2 \mathrm{msec})$ of the paired tone stimulation experiment.

Statistics. Unless stated otherwise, all values are reported as the mean $\pm \mathrm{SD}$. The $\mathrm{BD}$, spike count, and first and last spike latencies (re stimulus onset) of a cell are reported for stimulation at $10 \mathrm{~dB}$ above threshold (in a few cases, $20 \mathrm{~dB}$ ). There was no correlation between the duration of the NE tone and the duration of the leading inhibition $(r=$ $0.034 ; p=0.7181)$ or persistent inhibition $(r=0.040 ; p=0.6686)$; hence values for individual cells were averaged across different NE tone durations. The duration of leading and persistent inhibition was compared at 


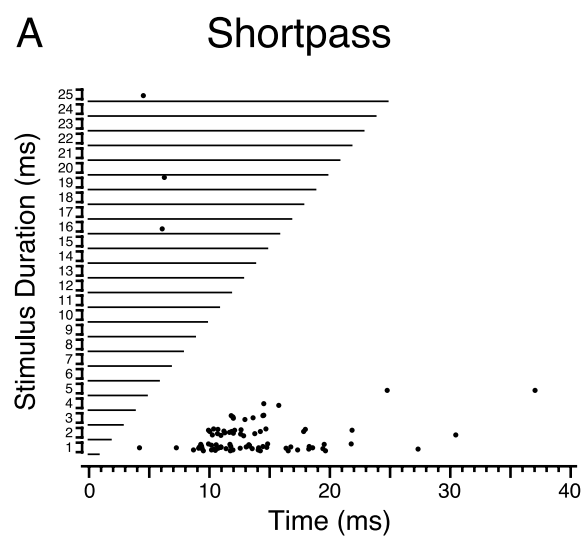

B

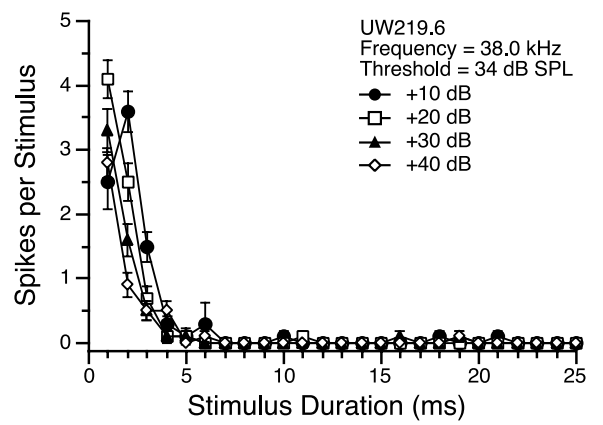

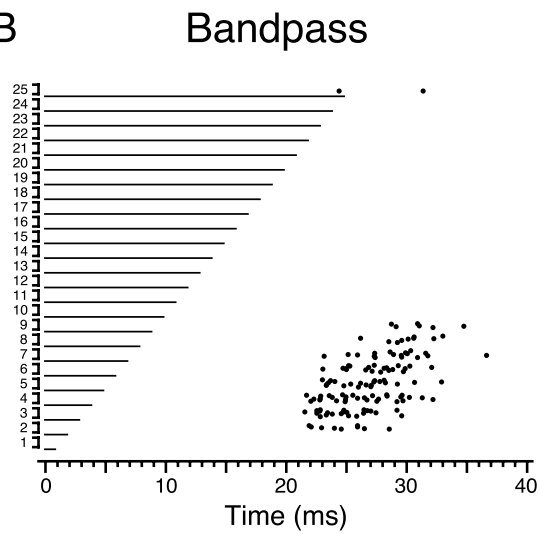

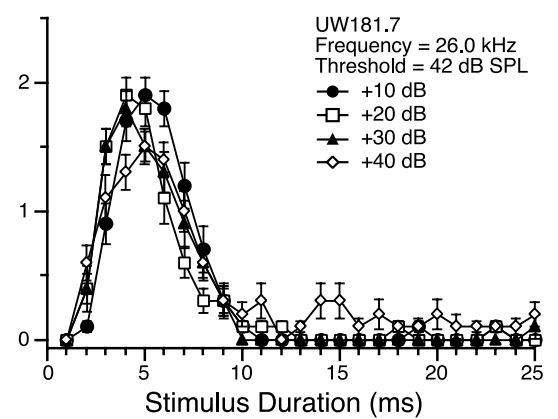

C Longpass
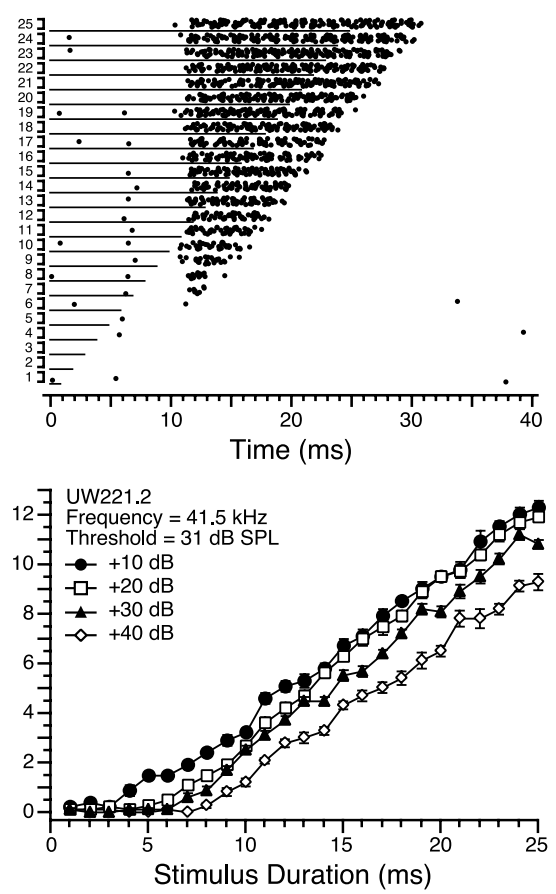

Figure 4. Examples of duration tuning. A, Short-pass neuron. B, Bandpass neuron. C, Long-pass neuron. Top row, Poststimulus rastergrams illustrating the timing of spikes in response to BEF tone pulses of variable duration presented at $30 \mathrm{~dB}$ above $B D$ threshold. Bottom row, Mean \pm SE spikes per stimulus as a function of stimulus duration at different sound levels relative to threshold. Note that duration selectivity is relatively stable with changes in stimulus amplitude. $A, C$, Fifteen trials per stimulus; $B, 20$ trials per stimulus.

different relative amplitudes of the BD and NE tones using a repeated measures ANOVA, with the difference in SPL as the within-subjects effect (superANOVA). The duration of leading inhibition was compared between cells with a one-way ANOVA using Sheffe's $F$ procedure for post hoc comparisons (Statview). All statistical tests used an experiment-wise error rate of $\alpha \leq 0.05$ (Zar, 1984).

\section{Results}

Types of duration selectivity

We recorded from 73 duration-tuned neurons. Of these, 35 $(48 \%)$ were short-pass duration-tuned (Fig. $4 A$ ), and $38(52 \%)$ were bandpass duration-tuned (Fig. $4 B$ ). Within the short-pass category, one neuron changed from short-pass at $10 \mathrm{~dB}$ to bandpass at $20 \mathrm{~dB}$ above the BD threshold. Within the bandpass category, 18 cells retained their bandpass tuning at both 10 and $20 \mathrm{~dB}$ above the BD threshold, whereas 20 cells switched from bandpass to short-pass tuning. Short-pass and bandpass neurons are interesting from a computational viewpoint, because the specificity of their response cannot be explained simply by integration of stimulus energy over time and therefore must require some form of neural inhibition.

We also recorded from three neurons that responded only to longer-duration sounds. Paired tone testing of the neuron in Figure $4 C$ revealed that a transient period of onset-evoked inhibition preceded the sustained excitation. In a section below, we will show how a combination of excitation and inhibition can create cells with long-pass duration selectivity. Because long-pass neurons do not have a single $\mathrm{BD}$, these cells are not included in our population statistics of duration-tuned neurons. Nevertheless, our observations on long-pass cells are relevant to the mechanisms that create short-pass and bandpass duration selectivity.
Frequency tuning and temporal discharge patterns of duration-tuned neurons

Figure $5 \mathrm{~A}$ shows that the BEFs of most duration-tuned neurons were in the frequency range from 25 to $50 \mathrm{kHz}$. This frequency band is important for target ranging in E. fuscus (Surlykke, 1992) and closely matches the frequencies present in the fundamental FM sweep of the echolocation call (Simmons et al., 1995; Surlykke and Moss, 2000). A behavioral audiogram of E. fuscus (Fig. $5 A$ ) (Koay et al., 1997) showed that neurons with the lowest thresholds mirrored the bat's behavioral sensitivity in the frequency range from 10 to $50 \mathrm{kHz}$. We found few duration-tuned cells with BEFs of $>50 \mathrm{kHz}$ and none with BEFs of $>64 \mathrm{kHz}$; the thresholds of these cells were well above the bat's behavioral sensitivity. We cannot rule out the possibility that we failed to adequately sample neurons from the higher frequency ranges. However, it is also possible that there are, in fact, very few durationtuned neurons in the bandwidth corresponding to the harmonic of the FM echolocation call. Figure $5 B$ shows that BDs varied between 1 and $8 \mathrm{msec}$, with the largest span in the frequency range from 25 to $45 \mathrm{kHz}$. Most neurons $(65 ; 89 \%)$ were selective for tones $\leq 4 \mathrm{msec}$ in duration. In general, short-pass neurons had short BDs, and bandpass cells had longer BDs (also see Fig. 13A).

Two aspects of response timing, latency and duration of the spike train, are important to examine, because they may be relevant for timing mechanisms at higher levels of auditory processing. Figure $5 C$ shows that response latency was, without exception, always longer than the BD. Cells with similar BDs had a wide range of first spike latencies. For example, cells with a $2 \mathrm{msec} B D$ had latencies ranging from $\sim 8$ to nearly $27 \mathrm{msec}$. Figure $5 D$ plots $\mathrm{BD}$ as a function of the average number of spikes per stimulus at $\mathrm{BD}$, reflecting the duration of the excitatory response. For many 

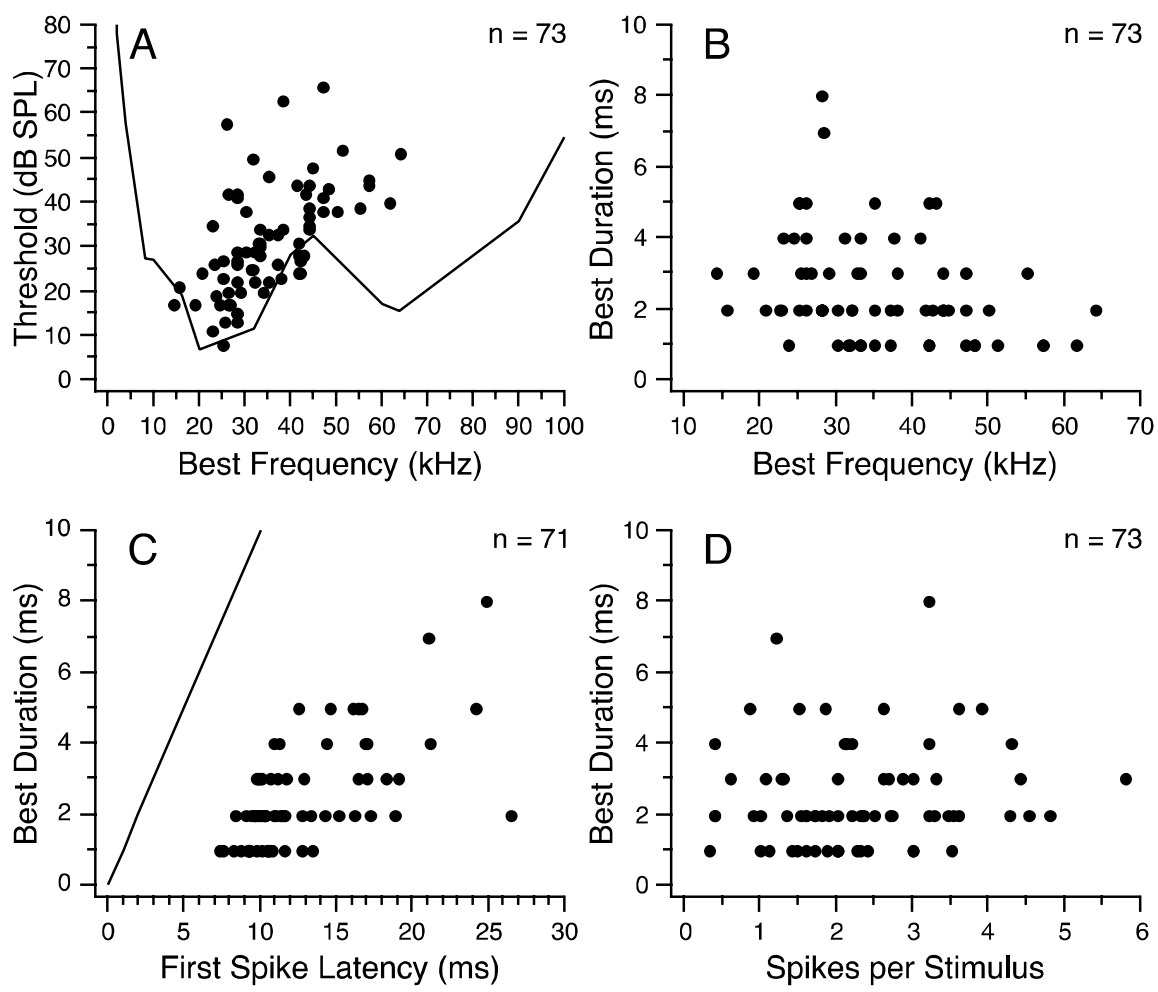

Figure 5. Response properties of duration-tuned neurons. $A$, Thresholds at $B D$ as a function of $B E F$ compared with the average behavioral audiogram of $E$. fuscus (solid line) from Koay et al. (1997). B, Cells with similar BEFs have a wide range of BDs. C, BD plotted against median first spike latency with regard to stimulus onset. Solid line, 1:1 line. $D, B D$ as a function of the average number of spikes per stimulus, an indicator of response burst duration $(r=0.136 ; p=0.2690)$.

duration-tuned neurons, the duration of the spike burst exceeded the stimulus duration. This suggests that the cells have long EPSPs, attributable to multiple excitatory synaptic inputs, intrinsic membrane properties, or both. There was no correlation between $\mathrm{BD}$ and spike count (Fig. 5D) or between $\mathrm{BD}$ and the duration of the excitatory spike burst, as measured by the last spike latency minus the first spike latency (data not shown).

\section{Short-pass and bandpass cells respond at signal offset}

All short-pass and bandpass cells responded after the offset of the stimulus. Of 73 duration-tuned neurons, 65 (89\%) were clearly offset responders in that their first spike latency increased as the duration of the tone increased (Fig. $4 A, B$ ). Figure $6 A$ shows dot rasters from a bandpass neuron with a BD of $4 \mathrm{msec}$. At stimulus durations of $>12 \mathrm{msec}$, the cell was virtually unresponsive. The first spike latency of the cell increased nearly linearly with increasing signal duration at stimulus durations of $>4 \mathrm{msec}$. At durations of 1-4 msec, first spike latency did not increase in proportion to sound duration. The nearly constant latency for short sound durations (1-4 msec) has not been shown previously. This nonproportional latency shift can be explained if we assume that the inhibitory component (IPSP) in this cell has a minimum duration; hence the time to rebound has a minimum latency. Therefore, spikes do not follow stimulus offset until after stimulus duration exceeds this minimum.

Of the 65 duration-tuned neurons with an offset response, 32 (49\%) showed evidence of an additional weak, onset-evoked excitation. An example of such a response pattern is shown in Figure $6 \mathrm{~B}$. For durations ranging from 1 to $6 \mathrm{msec}$, the first spike latency of the cell increased in a nearly linear manner with increasing stimulus duration. However, for stimulus durations of $\geq 4 \mathrm{msec}$, the cell also responded with occasional spikes that had a constant latency of $\sim 9 \mathrm{msec}$. Our interpretation is that the onset discharge represents spikes that managed to "break through" the onsetevoked inhibition. In other words, the initial portion of the inhibition in these cells is slightly weaker than the onset-evoked excitation. In cells that had no breakthough spikes time-locked to the onset of the stimulus, the inhibition must have been strong enough to completely counteract the onset-evoked excitation.

\section{Paired tone testing}

We tested 37 neurons with pairs of tones of the same frequency but different durations. Short-pass and bandpass neurons responded similarly in that the presentation of an NE tone suppressed the spikes evoked by a BD tone when the two tones were close together in time. Figure 7 shows the responses of a short-pass neuron ( $\mathrm{BD}, 2 \mathrm{msec})$ to paired tone stimulation as a series of vertically stacked dot raster displays. In Figure 7, the BD tone first precedes the NE tone (bottom), then merges with it, forming a single composite stimulus with a pedestal (gray box; see Materials and Methods), and then follows the NE tone (top). The top $x$-axis shows the gap between the two stimuli (i.e., interstimulus interval). The bottom $x$-axis shows the relative time between the offset of the BD tone and the onset of the NE tone. Time 0 is the onset of the NE tone and is the first point at which the two tones become contiguous. Negative times indicate when the offset of the BD tone preceded the onset of the NE tone; positive times indicate when it followed the onset of the NE tone. Because the amplitude of the $2 \mathrm{msec}$ tone was $10 \mathrm{~dB}$ higher than that of the $20 \mathrm{msec}$ tone, the two signals had the same energy. Moreover, an amplitude increment or pedestal always resulted whenever the BD and NE tones overlapped and summed to form a composite stimulus. Spikes were time-locked to the presentation of the BD tone but not to the NE tone. As the offset of the BD tone approached the onset of the NE tone, spikes were progressively eliminated from the end of the spike train. The spike deletion began when the offset of the BD tone preceded the onset of the NE tone by $\sim 8 \mathrm{msec}$. When the signals became contiguous but nonoverlapping, spikes were completely eliminated. Responses to the composite stimulus remained suppressed for most temporal positions of the pedestal. Spikes began to reemerge when the pedestal was $\sim 16 \mathrm{msec}$ past the onset of the composite tone. Responses recovered completely once the $\mathrm{BD}$ tone followed the NE tone.

These data provide evidence that the NE tone evoked inhibition that suppressed the spikes evoked by the BD tone. The pattern and timing of the progressive spike loss indicate that the inhibition was evoked by the onset of the NE tone. The fact that spikes were suppressed while there was still a gap between the leading $\mathrm{BD}$ tone and the lagging NE tone indicates that the inhibition evoked by the NE tone had a shorter latency than the excitation evoked by the BD tone. The observation that spikes were suppressed throughout most of the composite stimulus, 

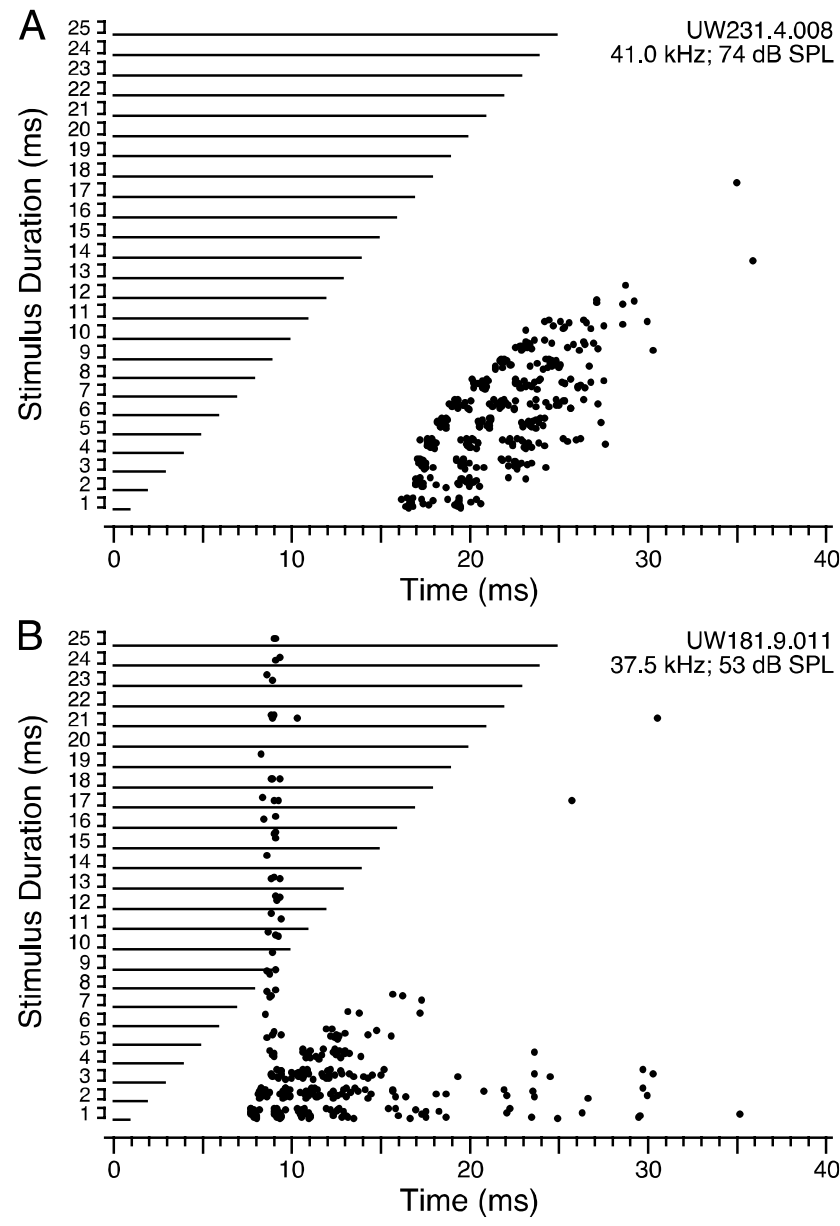

Figure 6. Temporal response patterns of two duration-tuned neurons. A, Poststimulus rastergram illustrating the offset response of a bandpass neuron with a $B D$ of $4 \mathrm{msec}$. At and above $B D$, the first spike latency increased as the duration of the tone pulse was lengthened, tracking the offset of the stimulus. $B$, Poststimulus rastergram showing the offset response plus onset breakthrough pattern of a short-pass neuron with a BD of $1 \mathrm{msec}$. For 1- 6 msec tones, the first spike latency tracked the offset of the stimulus; however, for $4-25$ msec tones, the cell occasionally responded with spikes time-locked to the onset of the stimulus. The latencies of the onset breakthrough spikes were longer than the latencies of the spikes in response to tones of 1-3 msec, suggesting that inhibition precedes excitation. All stimuli were BEF tone pulses of variable duration presented at $30 \mathrm{~dB}$ above $\mathrm{BD}$ threshold; 15 trials per stimulus.

when the $\mathrm{BD}$ and $\mathrm{NE}$ tones summed to produce a single tone with a pedestal, indicates that the inhibition was sustained for the duration of the composite stimulus. The observation that the pedestal evoked spikes only if it occurred near the end of the composite stimulus suggests that the sustained inhibition was strongest at its onset and then gradually decayed. In the next sections, we quantify these properties of the inhibition.

\section{Latency and duration of spike suppression}

Figure 8 shows spike counts and latency measurements from the same neuron shown in Figure 7 and illustrates how we quantified temporal features of the inhibition. The average baseline first and last spike latencies of the cell (with regard to BD tone onset) were $10.7 \pm 1.7$ and $15.6 \pm 2.4 \mathrm{msec}$, respectively. The average number of spikes per stimulus declined as the gap between the leading BD tone and the lagging NE tone decreased, eventually falling to zero when the two tones became contiguous. In the composite stimulus, spike counts began to increase when the offset of the pedestal was $16 \mathrm{msec}$ past the onset of the composite tone but did not return to baseline levels until there was again a gap between the

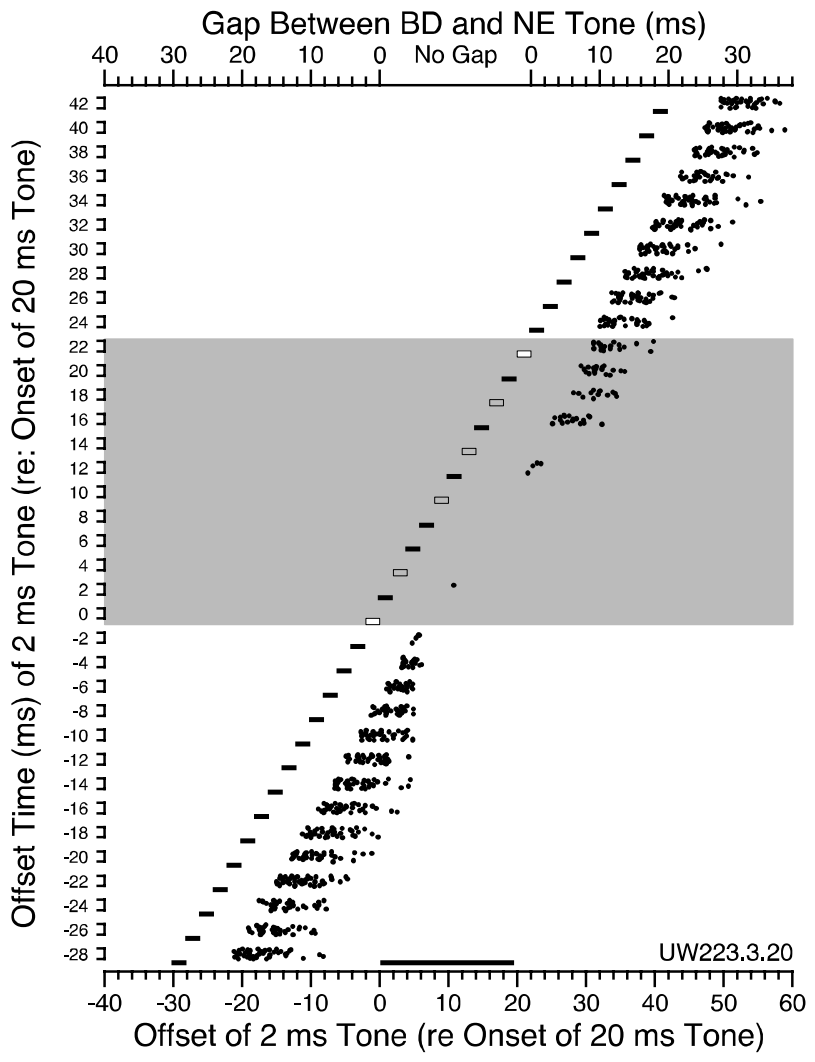

Figure 7. Paired tone suppression in a short-pass duration-tuned neuron. The number of spikes per BD tone stimulus began to decline while there was still a gap between the leading BD tone and the lagging NE tone. The last spikes of the response burst were the first to be deleted. Responses were maximally suppressed when the pedestal was in the first half of the composite stimulus but began to recover as the pedestal moved toward the end of the composite stimulus. Responses recovered completely when there was again a gap between the leading NE tone and the lagging BD tone. The two tones, illustrated as bars, were presented at the BEF of the cell. The 2 msec bars with a white fill indicate two time intervals when the BD tone was contiguous with but did not overlap the NE tone. The 2 msec bars with a gray fill indicate four time intervals when the amplitude of the pedestal in the composite stimulus was below criterion for inclusion in the summary plots of Figure 8 . BD tone duration, $2 \mathrm{msec}$; NE tone duration, $20 \mathrm{msec}$; $\mathrm{BD}$ and NE tone frequency, $44.0 \mathrm{kHz}$; BD tone threshold, $44 \mathrm{~dB}$ SPL; BD tone amplitude, $64 \mathrm{~dB} \mathrm{SPL}$; NE tone amplitude, $54 \mathrm{~dB} \mathrm{SPL} ; 15$ trials per stimulus.

leading NE tone and the lagging BD tone. First spike latencies remained constant as the interstimulus interval between the leading $\mathrm{BD}$ tone and the lagging $\mathrm{NE}$ tone was decreased (Fig. $8 \mathrm{~A}$ ); however, when the pedestal was near the end of the composite stimulus and spikes began to reemerge, first spike latencies were significantly longer than baseline latencies and remained so until there was again a gap between the leading NE tone and the lagging BD tone. Last spike latencies clearly decreased as the interstimulus interval between the leading $\mathrm{BD}$ tone and the lagging $\mathrm{NE}$ tone decreased (Fig. $8 B$ ). When the pedestal was near the end of the composite stimulus and spikes began to reemerge, last spike latencies were not noticeably different from baseline values.

Changes in the average last spike latency of the cell, when the offset of the $\mathrm{BD}$ tone preceded the onset of the NE tone, were used to measure the effective start time of the inhibition evoked by the $\mathrm{NE}$ tone relative to its onset. The first time interval at which the average last spike latency decreased by $>1$ SD relative to baseline served as the criterion for the start of the suppression. For the neuron in Figures 7 and 8, the first significant decrease in average last spike latency occurred when the offset of the BD tone preceded the onset of the NE tone by $6 \mathrm{msec}\left(T_{1}=-6 \mathrm{msec}\right.$; 

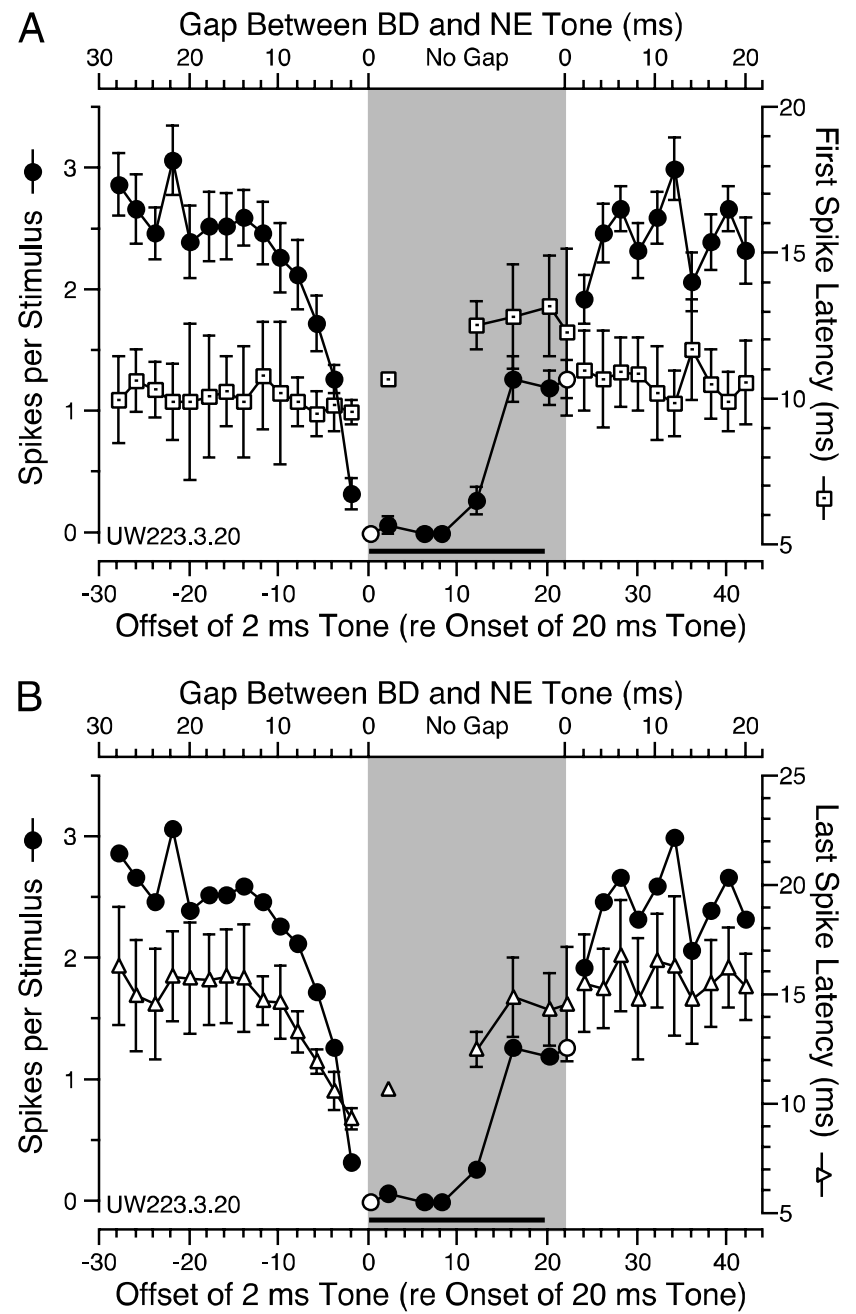

Figure 8. Spike count and latency plots for paired tone stimulation (data from Fig. 7). $A$, Mean \pm SE spikes per BD tone or pedestal (left $y$-axis, filled circles) and mean \pm SD first spike latency with regard to stimulus onset (right $y$-axis, open squares) as a function of the time between the offset of the BD tone and the onset of the NE tone. The number of action potentials evoked by the BD tone began to decline before its offset was contiguous with the onset of the NE tone. $B$, Spikes per stimulus (as in $A$; error bars are omitted for clarity), and last spike latency with regard to stimulus onset (right $y$-axis, open triangles) as a function of the time between the offset of the BD tone and the onset of the NE tone. The last spike latency of the cell began to decrease as the gap between the leading $B D$ tone and the lagging NE tone decreased because of the progressive deletion of spikes from the end of the response burst (see Fig. 7). The duration of the NE tone is illustrated with a black bar; the BD tone is not shown. Circles with a white fill are spike counts at the two time intervals when the BD tone was contiguous with but did not overlap the NE tone. The gray box indicates the range of times over which the BD tone was contiguous with or overlapped the BD tone to form a single composite stimulus with an amplitude increment (i.e., a pedestal). In this and similar figures, pedestal data that were not within $3 \mathrm{~dB}$ of maximum stimulus amplitude were omitted (see Testing with tone pairs); 15 trials per stimulus.

Fig. $8 B$ ). By adding $T_{1}$ to the baseline last spike latency of the cell $\left(L_{\text {last }}=15.6 \mathrm{msec}\right)$ and subtracting the duration of the BD tone ( $D=2 \mathrm{msec}$ ), the start time of the inhibition and hence its latency were calculated to occur $7.6 \mathrm{msec}$ after the onset of the NE tone. Therefore, inhibition preceded the baseline excitatory first spike latency of the cell $\left(L_{\text {first }}=10.7 \mathrm{msec}\right)$ by $3.1 \mathrm{msec}$.

Changes in the average first spike latency of the cell, when the offset of the BD tone (or pedestal) followed the onset of the NE tone (or composite stimulus), were used to measure the effective end time of the inhibition evoked by the NE tone relative to its onset. The last time interval at which the average first spike la- tency remained $>1 \mathrm{SD}$ above baseline served as the criterion for the end of the suppression. For the neuron in Figures 7 and 8, the last time interval at which the average first spike latency was significantly longer than baseline was when the offset of the pedestal was $22 \mathrm{msec}$ past the onset of the composite stimulus $\left(T_{2}=\right.$ $22 \mathrm{msec}$; Fig. $8 \mathrm{~A}$ ). By adding $T_{2}$ to the baseline first spike latency of the cell $\left(L_{\text {first }}=10.7 \mathrm{msec}\right)$ and subtracting the duration of the BD tone $(D=2 \mathrm{msec})$, the end time of the inhibition was calculated to occur $30.7 \mathrm{msec}$ after the onset of the NE tone. Subtracting from this the start time of the inhibition $\left(T_{\text {start }}=7.6 \mathrm{msec}\right)$ resulted in a total duration of inhibition of $23.1 \mathrm{msec}$. Therefore, inhibition persisted $3.1 \mathrm{msec}$ longer than the duration of the 20 msec NE tone. We used these methods to quantify the duration of leading, sustained, and persistent inhibition in all cells to obtain population statistics.

\section{Time course of inhibition}

According to the model of duration selectivity (Fig. 1), onsetevoked inhibition is sustained for the duration of the stimulus. This hypothesis was tested in 26 neurons by varying the duration of the NE tone. If the inhibition were sustained, then its duration should systematically increase as the duration of the NE tone was increased.

An example of such a manipulation on a bandpass neuron with a $\mathrm{BD}$ of $2 \mathrm{msec}$ is illustrated in Figure 9. As predicted, the duration of spike suppression systematically lengthened as the duration of the NE tone was increased. Of 26 short-pass and bandpass cells that were tested with NE tones of different durations, all showed clear and systematic increases in the duration of spike suppression with increasing NE tone duration. Because the duration of inhibition was also affected by the relative amplitudes of the BD and NE tones, we analyzed the effects of varying BD tone amplitude on spike suppression.

\section{Effect of BD tone amplitude on strength and timing of inhibition}

When the two tones were equal in amplitude and when the BD tone was $10 \mathrm{~dB}$ above the NE tone, there was a strong correlation between the duration of spike suppression and the duration of the NE tone (Fig. 10). All points on these two curves fall above the 1:1 line, indicating that inhibition persisted longer than the duration of the NE tone; however, the duration of spike suppression was always longer when the $\mathrm{BD}$ and $\mathrm{NE}$ tones were equal in amplitude than when the $\mathrm{BD}$ tone was $+10 \mathrm{~dB}$ with regard to the $\mathrm{NE}$ tone. When the $\mathrm{BD}$ tone was $20 \mathrm{~dB}$ above the NE tone, the curve falls below the 1:1 line at NE tone durations of $\geq 30 \mathrm{msec}$, indicating that inhibition did not increase in proportion to NE tone duration. Thus, although inhibition evoked by the NE tone was sustained within the range of NE tones durations tested, these findings suggest that its strength waned toward the end of a long duration stimulus.

Experiments that systematically changed the amplitude of the $\mathrm{BD}$ tone relative to that of the NE tone provide additional evidence that inhibition was strongest at onset and then gradually decayed. The hypothesis was that increasing the amplitude of the $\mathrm{BD}$ tone should increase the probability that excitation evoked by the $\mathrm{BD}$ tone (or the pedestal) would overcome the inhibition evoked by the NE tone (or the long-duration composite stimulus). At any given amplitude of the $\mathrm{BD}$ tone, the duration of spike suppression would provide an estimate of the relative strength of inhibition at different time intervals relative to the onset of the NE tone. This hypothesis was tested in 28 duration-tuned neurons. Figure 11 shows an example of such an experiment in a 

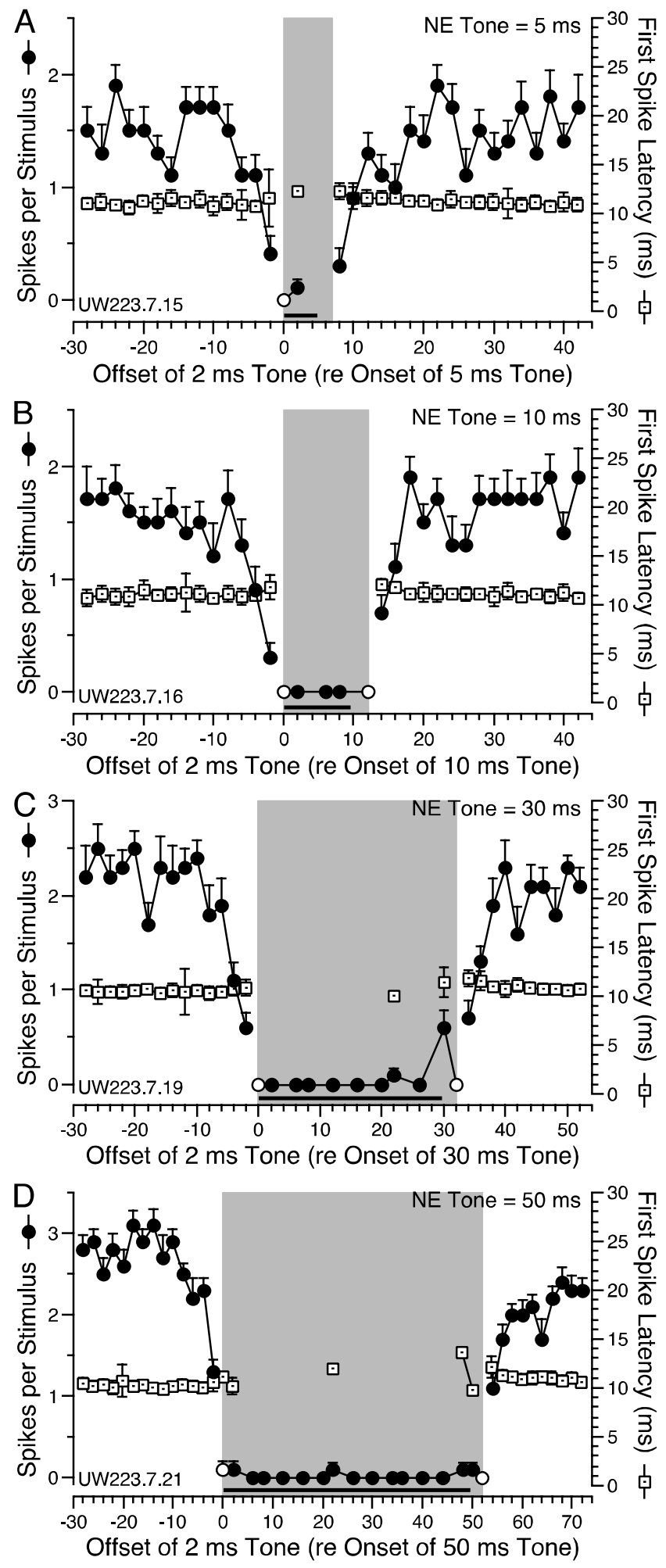

Figure 9. Spike suppression in a bandpass neuron as a function of NE tone duration. Lengthening the duration of the NE tone from 5 to 50 msec systematically increased the period of spike suppression from $8.6 \mathrm{msec}(A)$ to $14.5 \mathrm{msec}(B), 37.6 \mathrm{msec}(C)$, and $58.6 \mathrm{msec}(D)$. Spike count and latency plots are as in Figure 8 A. BD tone duration, $2 \mathrm{msec} ; \mathrm{BD}$ and NE tone frequency, $28.0 \mathrm{kHz} ; \mathrm{BD}$ tone threshold, $15 \mathrm{dBSPL} ; \mathrm{BD}$ tone and NE tone amplitude, $25 \mathrm{~dB} \mathrm{SPL} ; 15$ trials per stimulus.

short-pass neuron with a BD of 2 msec. Spikes were suppressed under all conditions when the pedestal occurred during the early part of the composite stimulus. As the amplitude of the pedestal was increased, spikes began to reemerge at progressively earlier

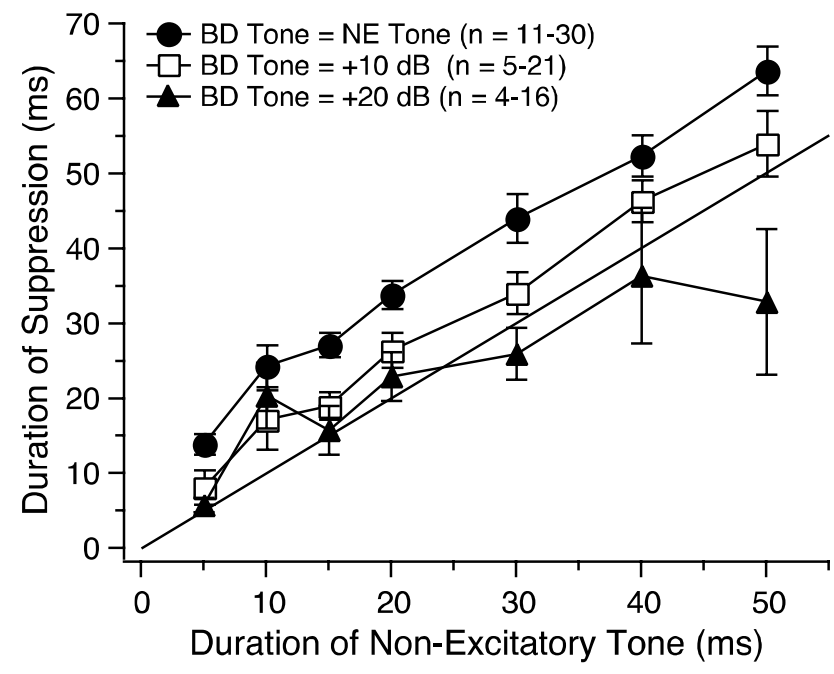

Figure 10. Average duration of spike suppression as a function of NE tone duration and BD tone amplitude for all neurons. For every amplitude of the BD tone, the total duration of spike suppression increased as the duration of the NE tone increased. When the BD and NE tones were equal in amplitude ( filled circles; $r=0.814 ; p<0.0001$ ), all points fell above the 1:1 line (straight line) showing that spike suppression persisted longer than the duration of the NE tone. When the amplitude of the BD tone was increased by $10 \mathrm{~dB}$ (open squares; $r=0.799 ; p<$ 0.0001 ), the duration of spike suppression decreased, but all points remained at or above the 1:1 line. When the amplitude of the $\mathrm{BD}$ tone was increased by $20 \mathrm{~dB}$ ( filled triangles; $r=0.458$; $p=0.0005$ ), the duration of spike suppression was shorter than the duration of the NE tone at durations of $\geq 30 \mathrm{msec}$, where the triangles fall below the 1:1 line.

pedestal times. The difference between the amount of spike suppression at the onset and offset of the composite stimulus can be seen in a different way, when the $\mathrm{BD}$ tone is contiguous with either the onset or the offset of the NE tone (Fig. $11 B-D$, open circles); spikes were evoked only when the BD tone immediately followed the NE tone. Both results suggest that inhibition evoked by the NE tone was strongest at signal onset but then gradually waned.

Of 28 short-pass and bandpass cells tested with different BD tone (or pedestal) amplitudes, 22 (79\%) displayed an inverse relationship between the period of spike suppression and the amplitude of the BD tone (or pedestal). This relationship held regardless of whether the response of the cell began to recover within the composite stimulus or only after the $\mathrm{BD}$ tone followed the NE tone. For five cells (18\%), the duration of spike suppression first increased and then decreased as the amplitude of the BD tone increased. In one cell (3\%), the duration of spike suppression increased when the $\mathrm{BD}$ tone was raised from 0 to $+10 \mathrm{~dB}$ with regard to the NE tone.

Figure 12 summarizes the amplitude-dependent changes in the duration of leading and persistent inhibition. When the $\mathrm{BD}$ and NE tones were equal in amplitude, 32 (94\%) of 34 neurons had leading inhibition, with the average difference in the distribution of first spike latency minus the latency of inhibition being $3.9 \pm 2.9 \mathrm{msec}$ (Fig. 12 A). When the BD tone was $10 \mathrm{~dB}$ above the NE tone, the proportion of cells with leading inhibition decreased to $78 \%$, and the average latency difference declined to $2.9 \pm 2.9$ msec (Fig. $12 \mathrm{~B}$ ). When the BD tone was $20 \mathrm{~dB}$ above the NE tone, $82 \%$ of cells showed leading inhibition and the distribution of first spike latency minus the latency of inhibition was not markedly changed ( $2.8 \pm 3.0 \mathrm{msec}$; Fig. $12 \mathrm{C})$. The change in the distribution of first spike latency minus the latency of inhibition was statistically significant (repeated measures ANOVA, $F_{(2)}=7.953$; $p=0.0013)$; however, the absolute change was quite small $(<1.1$ $\mathrm{msec}$ ). 

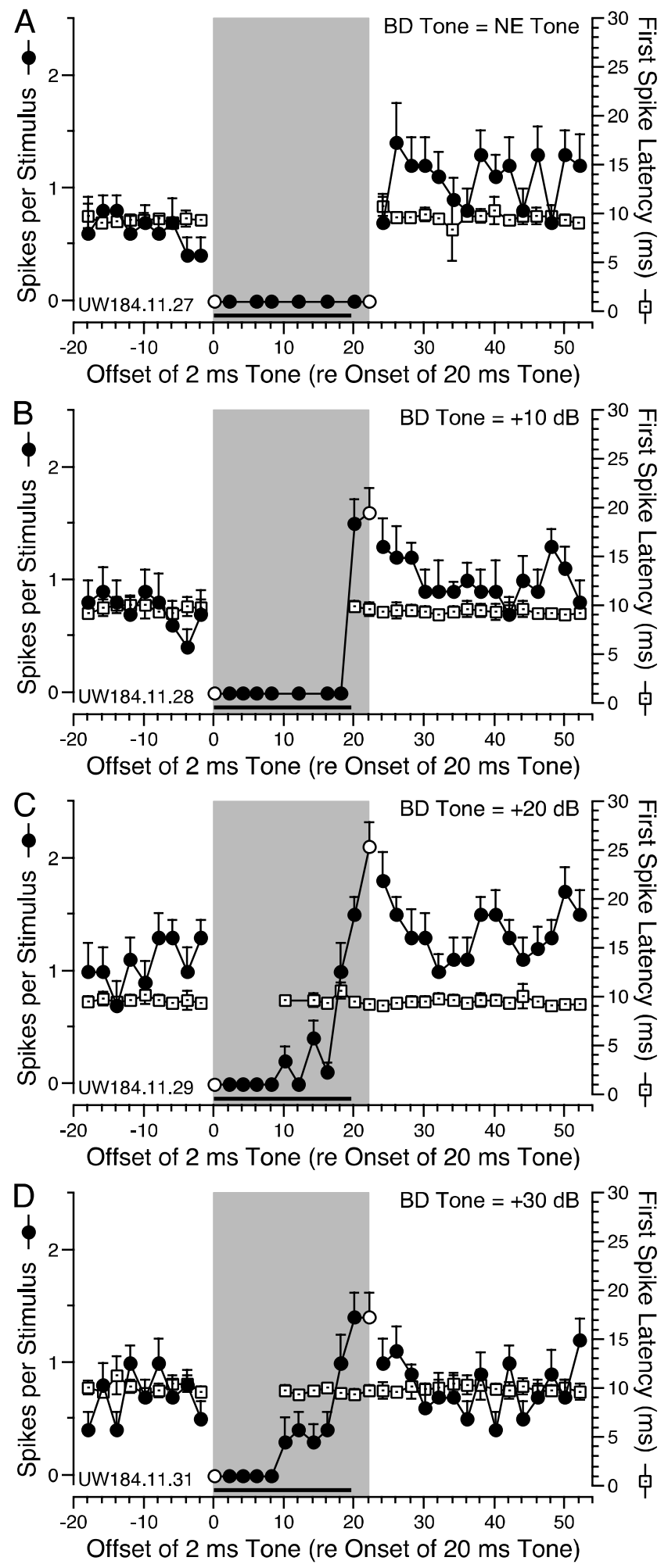

Figure 11. Spike suppression and offset facilitation in a short-pass neuron as a function of $B D$ tone amplitude. Increasing the amplitude of the $B D$ tone from +0 to $+30 \mathrm{~dB}$ with regard to the NE tone systematically decreased the period of spike suppression from $23.9 \mathrm{msec}(A)$ to 17.7 msec $(B), 17.6 \mathrm{msec}(C)$, and $7.9 \mathrm{msec}(D)$. Note that spike counts increased above baseline when the $B D$ tone (or pedestal) occurred at or near the offset of the NE tone (or composite stimulus), suggesting response facilitation. Spike count and latency plots are as in Figure 8 A. BD tone duration, 2 msec; NE tone duration, 20 msec; $B D$ and NE tone frequency, $31.5 \mathrm{kHz}$; $B D$ tone threshold, $25 \mathrm{~dB}$ SPL; BD and NE tone amplitude, $35 \mathrm{~dB} \mathrm{SPL;} 10$ trials per stimulus.
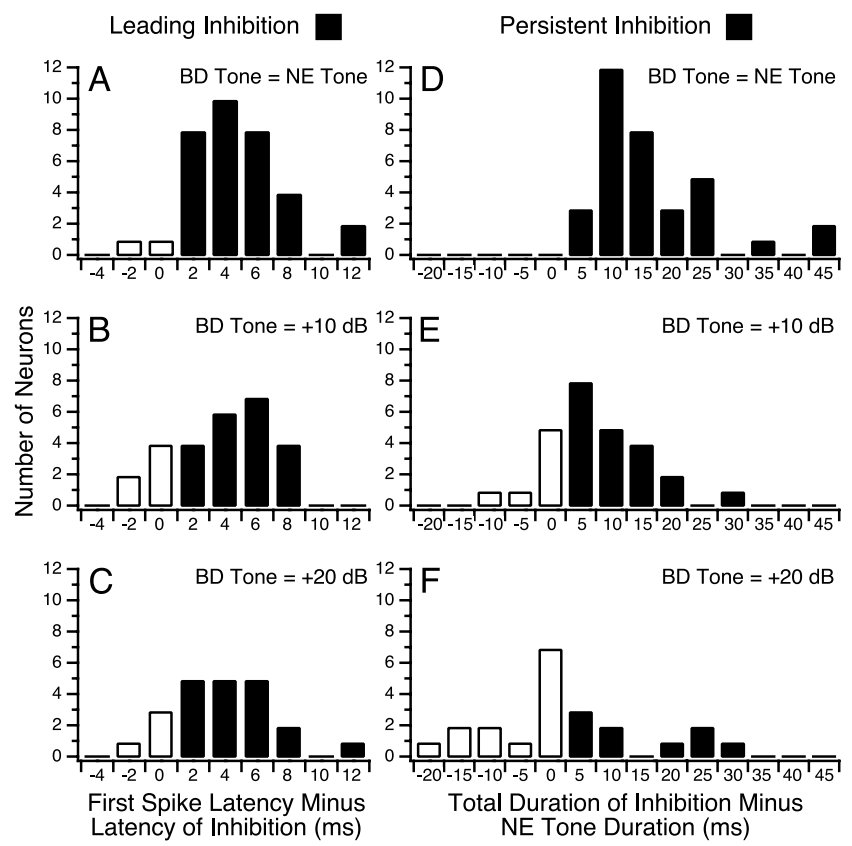

Figure 12. Leading and persistent inhibition at different relative amplitudes of the $B D$ and NE tones. Left column, Distribution of the difference between first spike latency and the latency of the inhibition evoked by the NE tone. Right column, Distribution of the difference between the total duration of the inhibition evoked by the NE tone and the duration of the NE tone. The numbers of neurons with leading and persistent inhibition are shown with black bars. Increasing the amplitude of the $B D$ tone had little effect on the number of neurons with leading inhibition $(A-C)$, but the number of neurons with persistent inhibition decreased $(D-F) . A, D$, $n=34 ; B, E, n=27 ; C, F, n=22$.

A similar analysis was conducted on the difference in time between the total duration of the inhibition evoked by the NE tone and the duration of the NE tone. When the $\mathrm{BD}$ and NE tones were equal in amplitude, all neurons showed persistent inhibition, and the average time difference was $14.1 \pm 10.0 \mathrm{msec}$ (Fig. $12 \mathrm{D})$. When the $\mathrm{BD}$ tone was $10 \mathrm{~dB}$ above the NE tone, $26 \%$ of neurons no longer showed persistent inhibition, and the mean difference decreased to $4.9 \pm 8.4 \mathrm{msec}$ (Fig. 12E). When the BD tone was $20 \mathrm{~dB}$ above the NE tone, most neurons (59\%) no longer showed persistent inhibition, and the mean decreased to $0.8 \pm$ $13.4 \mathrm{msec}$ (Fig. 12F). The change in the distribution of the total duration of inhibition minus the duration of the NE tone was highly significant (repeated measures ANOVA, $F_{(2)}=28.249$; $p=0.0001)$. These data indicate that excitation evoked by the BD tone (or pedestal) can more easily overcome inhibition evoked by the NE tone when it occurs closer to the offset of the NE tone (or composite stimulus), thus providing further support for the idea that the inhibition evoked by the NE tone gradually decays.

Relation of leading inhibition to $\mathrm{BD}$, duration selectivity, and first spike latency

One implication of the model (Fig. 1) is that BD and the range of duration selectivity are created, in part, by the difference in latency between the onset-evoked inhibition and the onset-evoked excitation (i.e., by the time by which inhibition precedes excitation). At one extreme, neurons with short BDs would require little or no leading inhibition. At the other extreme, neurons with long BDs would require longer periods of leading inhibition.

Of the 32 neurons in Figure $12 \mathrm{~A}$ that showed leading inhibition when the $\mathrm{BD}$ and $\mathrm{NE}$ tones were equal in amplitude, the duration of leading inhibition was significantly correlated with 

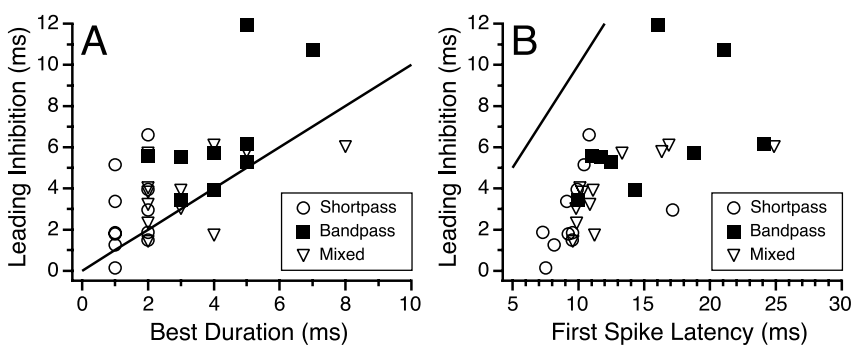

Figure 13. Relationship of leading inhibition to $B D$, first spike latency, and duration filter characteristic. $A$, Duration of leading inhibition was significantly correlated with $\mathrm{BD}(r=0.632$; $p<0.0001 ; n=32)$. $B$, Duration of leading inhibition was significantly correlated with median first spike latency with regard to stimulus onset $(r=0.646 ; p<0.0001 ; n=32)$. Each point is the average duration of leading inhibition measured across different NE tone durations with equal amplitude BD and NE tones. Solid line, 1:1 line.

$\mathrm{BD}$ and was also related to the duration filter characteristic (Fig. $13 A$ ). Short-pass neurons had the shortest leading inhibition $(2.8 \pm 1.9$ msec; $n=11)$; bandpass cells had the longest leading inhibition ( $6.5 \pm 2.9 \mathrm{msec} ; n=9)$; and cells that changed their duration selectivity from bandpass to short-pass had intermediate levels of leading inhibition ( $3.9 \pm 1.7 \mathrm{msec} ; n=12)$. The duration of the leading inhibition differed significantly among the three groups of cells (ANOVA, $F_{(2)}=7.616 ; p=0.0022$ ).

Because $\mathrm{BD}$ is related to first spike latency (Fig. $5 C$ ), and because cells tuned to longer BDs have longer durations of leading inhibition (Fig. 13A), this implies that first spike latency should also be related to leading inhibition and, in turn, duration filter characteristic. Consistent with this notion, there was a significant correlation between first spike latency and the duration of leading inhibition (Fig. 13B). Cells with short first spike latencies had smaller durations of leading inhibition than cells with longer first spike latencies. Indeed, $42 \%$ of the variation in the data was explained by the correlation.

\section{Offset facilitation}

A component of the model that has not yet been considered is offset excitation (Grothe et al., 2001) or rebound from inhibition, which is known to occur in some IC neurons (Torterolo et al., 1995; Pedemonte et al., 1997; Peruzzi et al., 2000; Sivaramakrishnan and Oliver, 2001). If offset-evoked depolarization is large enough, it should be observed as a facilitation of the response to the $\mathrm{BD}$ tone (or pedestal) at certain times near the offset of the NE tone (or composite stimulus). Figure 11 shows an example of a neuron in which this type of facilitation is clearly present. For this neuron, when the BD tone immediately followed the NE tone, the number of spikes evoked was elevated relative to baseline. Of 37 short-pass and bandpass cells tested with paired tone stimulation, $10(27 \%)$ showed evidence of spike facilitation when the pedestal was near the end of the composite stimulus or when the BD tone was contiguous with or closely followed the offset of the NE tone. It could be argued that offset facilitation was attributable to waveform summation when the $\mathrm{BD}$ and $\mathrm{NE}$ tones were exactly in phase. However, the BD and NE tones were also in phase when the onset of the pedestal began at the onset of the composite stimulus, and facilitation was never observed. Moreover, the fact that response facilitation was observed at temporal relationships when there was no physical overlap between the BD and NE tones in itself argues against waveform interference as a confounding factor.
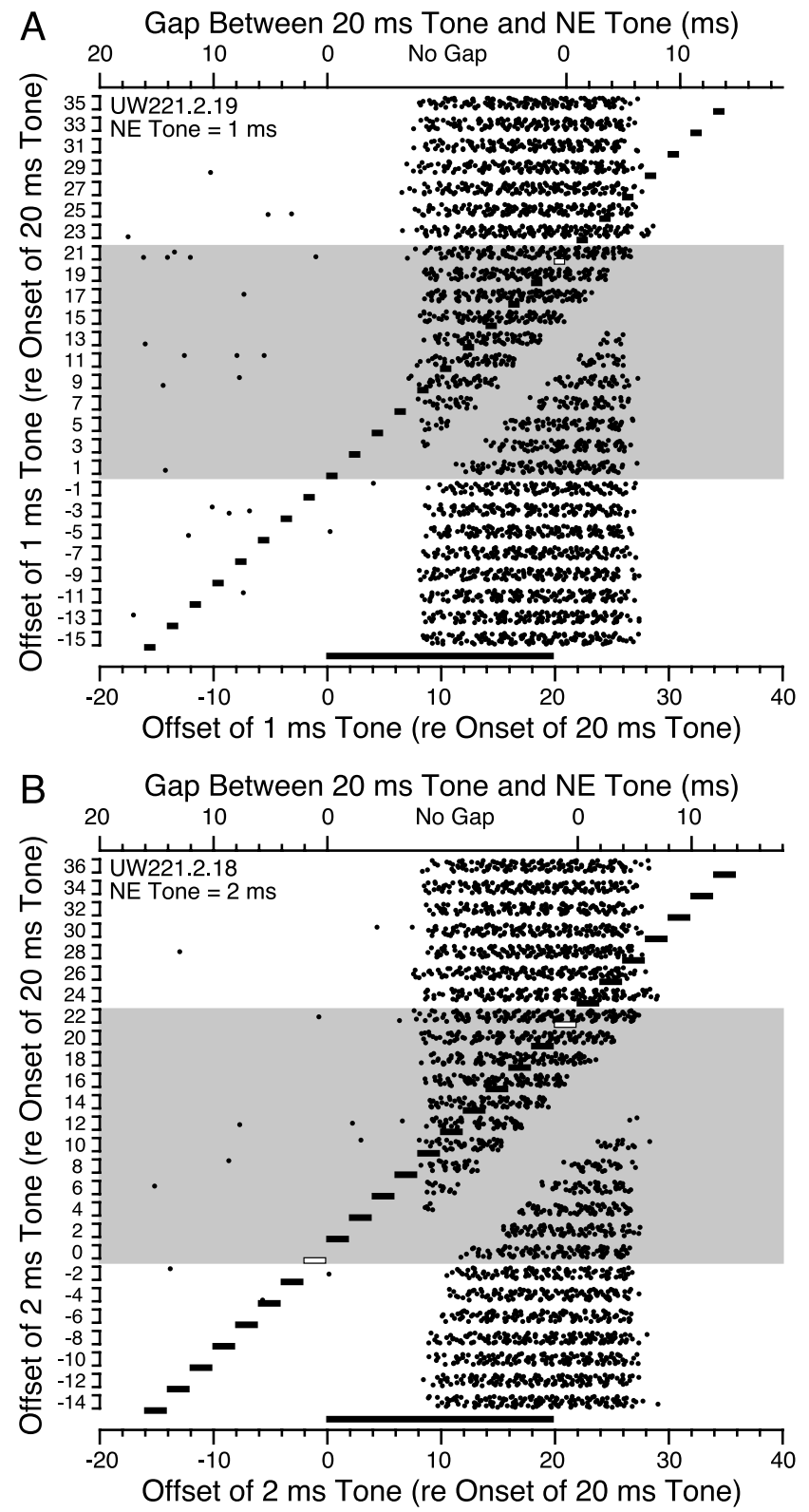

Figure 14. Paired tone suppression in a long-pass duration-selective neuron. $A$, Responses to a stationary 20 msec tone were suppressed for $7.5 \mathrm{msec}$ by the presentation of a roving $1 \mathrm{msec}$ tone. $B$, Responses to a stationary 20 msec tone were suppressed for $10.3 \mathrm{msec}$ by the presentation of a roving $2 \mathrm{msec}$ tone. Peristimulus rastergrams are as in Figure 7. $0 \mathrm{ne}, 2$, and $20 \mathrm{msec}$ tone frequency, $41.5 \mathrm{kHz} ; 20$ msec tone threshold, $31 \mathrm{~dB} \mathrm{SPL} ; 1$ and 2 msec tone amplitude, 71 $\mathrm{dB}$ SPL; 20 msec tone amplitude, $41 \mathrm{~dB}$ SPL; 15 trials per stimulus.

Early inhibition can create long-pass duration selectivity

Some neurons required a long duration stimulus to respond. Figure $4 C$ shows that long-pass selectivity was not attributable to temporal summation of stimulus energy. Not only did this cell fail to respond to short-duration sounds, but the minimum stimulus duration necessary to evoke a response increased with increasing stimulus amplitude. Paired tone stimulation revealed inhibition that was evoked by a short-duration stimulus (Fig. 14). A $20 \mathrm{msec}$ pulse that evoked a robust response was used as the probe tone, and a roving 1, 2, or $4 \mathrm{msec}$ tone was used as the NE tone. Spike suppression always began when the offset of the NE tone was simultaneous with or preceded the onset of the $20 \mathrm{msec}$ tone, indicating that inhibition arrived simultaneously with or slightly before excitation. When the NE tone was $1 \mathrm{msec}$, the 
average period of spike suppression was $7.5 \mathrm{msec}$ (Fig. 14A). When the NE tone was $2 \mathrm{msec}$, the average period of spike suppression was $10.3 \mathrm{msec}$ (Fig. 14B). When the NE tone was $4 \mathrm{msec}$, suppression lasted an average of $12.8 \mathrm{msec}$ (data not shown). At longer durations, the NE tone became excitatory. In Figure $4 C$, it can be seen that a few spikes managed to break through what appears to be transient onset-evoked inhibition occurring $\sim 6$ msec after stimulus onset and $\sim 6$ msec before the start of the sustained response. This is another example of how leading inhibition contributes to first spike latency.

Long-pass neurons are of interest in the present context because a component of the mechanism that creates short-pass and bandpass selectivity, leading inhibition, is also a mechanism for creating neurons that require a minimum duration to respond, with the minimum duration depending on the duration of the leading inhibition. Thus, onset-evoked, transient inhibition provides a mechanism for creating duration-selective neurons with minimum durations in the tens of milliseconds. In previous experiments in the IC of E. fuscus, we have encountered neurons that require sounds as long as $50 \mathrm{msec}$ to respond, so it is likely that these cells receive long-lasting inhibition that ends before the sustained excitatory input does.

\section{Discussion}

Neurons tuned for the duration of a stimulus have been found in the central auditory systems of a number of vertebrates, including frogs (Potter, 1965; Narins and Capranica, 1980; Hall and Feng, 1986; Gooler and Feng, 1992), mice (Brand et al., 2000), chinchillas (Chen, 1998), cats (He et al., 1997), and various species of echolocating bats (Jen and Schlegel, 1982; Pinheiro et al., 1991; Casseday et al., 1994; Condon et al., 1996; Galazyuk and Feng, 1997; Fuzessery and Hall, 1999). Neurons tuned to the duration of a stationary bar of light have also been found in areas 17 and 18 of the cat visual cortex (Duysens et al., 1996). One clue that the mechanism for duration tuning could be a general feature of sensory processing is that duration-tuned cells in both the auditory and visual systems usually respond at signal offset. The fact that duration-tuned neurons are present in more than one class of vertebrate and in more than one sensory modality also suggests that duration selectivity is a general property of sensory systems. All auditory neurons are tuned to frequency, and some are tuned to signal amplitude. Neurons that are duration-tuned have an additional neuronal filter for signal processing.

Because duration-tuned cells with similar BDs have different first spike latencies, they could serve as delay lines for higher auditory centers. For example, if the response of a delay-tuned neuron in the auditory thalamus (Olsen and Suga, 1991) depended on coincidence of inputs from duration-tuned neurons, then it would detect the delay of two sounds with specific durations. Because duration-tuned neurons are also tuned to frequency and, in some cases, signal amplitude, these variables add additional dimensions to their response specificity. Convergence of outputs with multiple dimensions of specificity could endow neurons at higher levels with selectively to complex sequences of sounds such as species-specific vocalizations (Leppelsack, 1978; Suga et al., 1978; Margoliash, 1983; Rauschecker et al., 1995; Wang et al., 1995; Mooney et al., 2001).

\section{Temporal properties of inhibition in duration selectivity}

Previous studies suggested a model in which duration tuning arose from the convergence and interaction of excitatory and inhibitory synaptic inputs offset in time (Casseday et al., 1994, 2000; Covey et al., 1996; Ehrlich et al., 1997). The present study focused on three issues concerning the temporal properties of the inhibition. The first was whether inhibition had a shorter latency than excitation. The second was whether inhibition was sustained and, if so, whether it was maintained with the same strength throughout the duration of the stimulus, whether it decayed, and whether it persisted beyond the duration of the stimulus. The third issue had to do with how the above properties of inhibition determined the duration-tuning characteristics of the cell.

First, the finding that the responses to a $\mathrm{BD}$ tone could be eliminated by an NE tone that followed the $\mathrm{BD}$ tone is clear evidence that inhibition precedes excitation. Our measurements showed that for most duration-tuned neurons, the onset-evoked inhibition had a shorter latency than the first spike latency of the cell. The results on leading inhibition are consistent with the finding that iontophoretic blocking of GABA or glycine receptors can shorten the response latency of many IC neurons, including duration-tuned neurons (Casseday et al., 2000; Fuzessery and Hall, 1999). In certain populations of IC neurons, the effects of leading inhibition on response latency may be small (Fuzessery et al., 2002).

Second, the results of the pedestal experiments indicate that inhibition is strongest at its onset and is sustained throughout the duration of a sound but gradually decays. At the smallest pedestal increment, spikes were suppressed for at least the duration of the composite stimulus. When the amplitude of the pedestal was increased, spikes were still completely suppressed when the pedestal occurred at the beginning of the composite stimulus but partially recovered when it occurred toward the end of the composite tone. This finding indicates that inhibition was strongest at stimulus onset and then gradually decayed. Although the model predicts that some excitatory summation should occur when the pedestal is in the initial portion of the composite stimulus (see Fig. $2 B$ ), evidently the inhibition evoked by the long-duration composite stimulus is so strong that it prevents spiking, the onset-evoked EPSP is weak, or both. Some cells exhibited facilitation after spike suppression. This finding is consistent with the idea that there is subthreshold excitation or rebound from inhibition at sound offset. Evidence for persistent inhibition was seen when spikes were suppressed when the BD tone followed the NE tone. Persistent inhibition has also been seen in experiments showing that blocking inhibition, especially GABAergic inhibition, often increased the period of responding of IC neurons (Casseday et al., 2000; Pollak and Park, 1993). The paired tone experiments reported here have allowed us to quantify the strength and time course of inhibition in a large sample of neurons and without any of the unwanted side effects of drug application.

Third, in the model of duration tuning, the latency and duration of the leading inhibition should, together with the latency and duration of the onset-evoked excitation, determine the BD of a neuron. Leading inhibition controls the minimum duration to which a neuron responds. In our data, the duration of leading inhibition was related to BD. Leading inhibition also correlated with the first spike latency of duration-tuned neurons. A relationship was also reflected in the duration filter characteristic of the neuron, with short-pass cells having the shortest leading inhibition and bandpass cells having the longest.

Long-pass neurons, like short-pass and bandpass neurons, receive short-latency, onset-evoked inhibition and delayed excitation. However, for long-pass neurons, the inhibition is transient, and the excitation is sustained, whereas for short-pass and bandpass neurons, the inhibition is sustained, and the excitation is 
transient. Thus, by reversing the temporal patterns of the inputs, it is possible to create different types of duration selectivity.

\section{Inhibitory control of temporal masking}

The inhibitory control of spike latency in neurons that respond at stimulus offset makes it possible for the response to one stimulus to coincide with, or even precede, excitation evoked by another stimulus that occurred earlier in time. This possibility depends on two kinds of timing mechanisms: multisynaptic delay lines that control the arrival times of excitatory and inhibitory inputs at the IC (Haplea et al., 1994; Klug et al., 2000) and integration of these inputs at the cell membrane. These mechanisms allow for the comparison of information from more than one time interval so that the cell does not fire until the entire temporal sequence and the subsequent integration is over. Our findings on these aspects of inhibition have implications for the psychophysical phenomena of temporal masking.

The design of our experiments was analogous to temporal masking experiments in psychophysics. From the point of view of a single neuron, the $\mathrm{BD}$ tone (or pedestal) served as the probe, and the NE tone served as the masker. We observed physiological equivalents of backward, simultaneous, and forward masking (Yost, 2000) and obtained evidence that neural inhibition could be involved in all three phenomena.

Suppression of spikes when the BD tone preceded the NE tone is equivalent to backward masking and was attributable to the leading inhibition evoked by the NE tone. In backward masking, a probe tone that precedes a masker tone may be undetectable for up to $50 \mathrm{msec}$ (Zwicker and Fastl, 1990). The fact that the latency of inhibition was shorter than that of excitation allowed the inhibition evoked by the NE tone to suppress the response to the previous $\mathrm{BD}$ tone. Leading inhibition has been observed in IC neurons regardless of whether or not they are duration tuned (Carney and Yin, 1989) and can last as long as $25 \mathrm{msec}$ (Park and Pollak, 1993; Covey et al., 1996).

Suppression of spikes when the BD and NE tones overlapped in time to form a single composite stimulus with a pedestal is equivalent to simultaneous masking and was attributable to sustained inhibition.

Suppression of spikes when the BD tone followed the NE tone is equivalent to forward masking and was attributable to the persistent inhibition evoked by the NE tone. In forward masking, a probe tone that follows a masker tone may be undetectable for up to $150 \mathrm{msec}$ (Zwicker and Fastl, 1990). Persistent inhibition has been observed in IC neurons regardless of whether or not they are duration-tuned (Faingold et al., 1991; Pollak and Park, 1993; Torterolo et al., 1995; Kuwada et al., 1997; Pedemonte et al., 1997; Klug et al., 1999) and can last as long as $100 \mathrm{msec}$ (Yin, 1994; Covey et al., 1996; Litovsky and Delgutte, 2002).

In human psychophysics, the time courses of backward and forward masking are asymmetrical, the time frame of backward masking being much shorter than that of forward masking. Likewise, in our results, leading and persistent inhibition were asymmetrical, with leading inhibition being shorter in duration than persistent inhibition. The importance of these results with respect to the mechanisms of temporal masking is that leading, sustained, and persistent inhibition immediately suggest a mechanism that could produce temporal masking.

\section{References}

Bauer EE, Klug A, Pollak GD (2000) Features of contralaterally evoked inhibition in the inferior colliculus. Hear Res 141:80-96.

Brand A, Urban A, Grothe B (2000) Duration tuning in the mouse auditory midbrain. J Neurophysiol 84:1790-1799.
Carney LH, Yin TCT (1989) Responses of low-frequency cells in the inferior colliculus to interaural time differences of clicks: excitatory and inhibitory components. J Neurophysiol 62:144-161.

Casseday JH, Ehrlich D, Covey E (1994) Neural tuning for sound duration: role of inhibitory mechanisms in the inferior colliculus. Science 264:847-850.

Casseday JH, Ehrlich D, Covey E (2000) Neural measurement of sound duration: control by excitatory-inhibitory interactions in the inferior colliculus. J Neurophysiol 84:1475-1487.

Casseday JH, Fremouw T, Covey E (2002) The inferior colliculus: a hub for the central auditory system. In: Integrative functions in the mammalian auditory pathway (Oertel D, Fay RR, Popper AN, eds), pp 238-318. New York: Springer.

Chen G-D (1998) Effects of stimulus duration on responses of neurons in the chinchilla inferior colliculus. Hear Res 122:142-150.

Condon CJ, White KR, Feng AS (1996) Neurons with different temporal firing patterns in the inferior colliculus of the little brown bat differentially process sinusoidal amplitude-modulated signals. J Comp Physiol [A] 178:147-157.

Covey E, Kauer JA, Casseday JH (1996) Whole-cell patch-clamp recording reveals subthreshold sound-evoked postsynaptic currents in the inferior colliculus of awake bats. J Neurosci 16:3009-3018.

Duysens J, Schaafsma SJ, Orban GA (1996) Cortical off response tuning for stimulus duration. Vision Res 36:3243-3251.

Ehrlich D, Casseday JH, Covey E (1997) Neural tuning to sound duration in the inferior colliculus of the big brown bat, Eptesicus fuscus. J Neurophysiol 77:2360-2372.

Faingold CL, Anderson CAB, Caspary DM (1991) Involvement of GABA in acoustically-evoked inhibition in inferior colliculus neurons. Hear Res 52:201-216.

Frederiksen E (1977) Condenser microphones used as sound sources. Brüel Kjær Technical Review 3:3-23.

Fuzessery ZM, Hall JC (1999) Sound duration selectivity in the pallid bat inferior colliculus. Hear Res 137:137-154.

Fuzessery ZM, Wenstrup JJ, Hall JC, Leroy S (2002) Inhibition has little effect on response latencies in the inferior colliculus. J Assoc Res Otolaryngol 4:60-73.

Galazyuk AV, Feng AS (1997) Encoding of sound duration by neurons in the auditory cortex of the little brown bat, Myotis lucifugus. J Comp Physiol [A] 180:301-311.

Gooler DM, Feng AS (1992) Temporal coding in the frog auditory midbrain: the influence of duration and rise-fall time on the processing of complex amplitude-modulated stimuli. J Neurophysiol 67:1-22.

Grothe B, Covey E, Casseday JH (2001) Medial superior olive of the big brown bat: neuronal responses to pure tones, amplitude modulations, and pulse trains. J Neurophysiol 86:2219-2230.

Griffin DR (1958) Listening in the dark. New Haven, CT: Yale UP.

Hall J, Feng AS (1986) Neural analysis of temporally patterned sounds in the frog's thalamus: processing of pulse duration and pulse repetition rate. Neurosci Lett 63:215-220.

Haplea S, Covey E, Casseday JH (1994) Frequency tuning and response latencies at three levels in the brainstem of the echolocating bat, Eptesicus fuscus. J Comp Physiol [A] 174:671-683.

He J, Hashikawa T, Ojima H, Kinouchi Y (1997) Temporal integration and duration tuning in the dorsal zone of cat auditory cortex. J Neurosci 17:2615-2625.

Jen PH-S, Schlegel PA (1982) Auditory physiological response properties of the neurones in the inferior colliculus of the big brown bat, Eptesicus fuscus. J Comp Physiol 1982:351-363.

Kalko EVK, Schnitzler H-U (1989) The echolocation and hunting behavior of Daubenton's bat, Myotis daubentoni. Behav Ecol Sociobiol 24:225-238.

Klug A, Bauer EE, Pollak GD (1999) Multiple components of ipsilateral evoked inhibition in the inferior colliculus. J Neurophysiol 82:593-610.

Klug A, Khan A, Burger RM, Bauer EE, Hurley LM, Yang L, Grothe B, Halvorsen MB, Park TJ (2000) Latency as a function of intensity in auditory neurons: influences of central processing. Hear Res 148:107-123.

Koay G, Heffner HE, Heffner RS (1997) Audiogram of the big brown bat (Eptesicus fuscus). Hear Res 105:202-210.

Kuwada S, Batra R, Yin TCT, Oliver DL, Haberly LB, Stanford TR (1997) Intracellular recordings in response to monaural and binaural stimulation of neurons in the inferior colliculus of the cat. J Neurosci 17:7565-7581. 
Leppelsack H-J (1978) Unit responses to species-specific sounds in the auditory forebrain center of birds. Fed Proc 37:2336-2341.

Litovsky RY, Delgutte B (2002) Neural correlates of the precedence effect in the inferior colliculus: effect of localization cues. J Neurophysiol 87:976-994.

Margoliash D (1983) Acoustic parameters underlying the responses of song-specific neurons in the white-crowned sparrow. J Neurosci 3:1039-1057.

Mooney R, Hoese W, Nowicki S (2001) Auditory representation of the vocal repertoire in a songbird with multiple song types. Proc Natl Acad Sci USA 98:12778-12783.

Olsen JF, Suga N (1991) Combination-sensitive neurons in the medial geniculate body of the mustached bat: encoding of target range information. J Neurophysiol 65:1275-1296.

Narins PM, Capranica RR (1980) Neural adaptations for processing the two-note call of the Puerto Rican tree frog, Eleutherodactylus coqui. Brain Behav Evol 17:48-66.

Park TJ, Pollak G (1993) GABA shapes a topographic organization of response latency in the mustache bat's inferior colliculus. J Neurosci 13:5172-5187.

Pedemonte M, Torterolo P, Velluti RA (1997) In vivo intracellular characteristics of inferior colliculus neurons in guinea pigs. Brain Res 759:24-31.

Peruzzi D, Sivaramakrishnan S, Oliver DL (2000) Identification of cell types in brain slices of the inferior colliculus. Neuroscience 101:403-416.

Pinheiro AD, Wu M, Jen PH-S (1991) Encoding repetition rate and duration in the inferior colliculus of the big brown bat, Eptesicus fuscus. J Comp Physiol [A] 169:69-85.

Pollak GD, Park TJ (1993) The effects of GABAergic inhibition on monaural response properties of neurons in the mustache bat's inferior colliculus. Hear Res 65:99-117.

Popper AN, Fay RR, eds (1995) Hearing by bats. New York: Springer.

Potter HD (1965) Patterns of acoustically evoked discharges of neurons in the mesecephalon of the bullfrog. J Neurophysiol 28:1155-1184.

Rauschecker JP, Tian B, Hauser M (1995) Processing of complex sounds in the macaque nonprimary auditory cortex. Science 268:111-114.
Shannon RV, Zeng F-G, Kamath V, Wygonski J, Ekelid M (1995) Speech recognition with primarily temporal cues. Science 270:303-304

Simmons JA, Stein RA (1980) Acoustic imaging in bat sonar: echolocation signals and the evolution of echolocation. J Comp Physiol 135:61-84.

Simmons JA, Saillant PA, Wotton JM, Haresign T, Ferragamo MJ, Moss CF (1995) Composition of biosonar images for target recognition by echolocating bats. Neural Networks 8:1239-1261.

Sivaramakrishnan S, Oliver DL (2001) Distinct K currents result in physiologically distinct cell types in the inferior colliculus of the rat. J Neurosci 21:2861-2877.

Stapells DR, Picton TW, Smith AD (1982) Normal hearing thresholds for clicks. J Acoust Soc Am 72:74-79.

Suga N, O'Neill WE, Manabe T (1978) Cortical neurons sensitive to combinations of information-bearing elements of biosonar signals in the mustached bat. Science 200:778 -781.

Surlykke A (1992) Target ranging and the role of time-frequency structure of synthetic echoes in big brown bats, Eptesicus fuscus. J Comp Physiol [A] 170:83-92.

Surlykke A, Moss CF (2000) Echolocation behavior of big brown bats, Eptesicus fuscus, in the field and laboratory. J Acoust Soc Am 108:2419-2429.

Torterolo P, Pedemonte M, Velluti RA (1995) Intracellular in vivo recording of inferior colliculus auditory neurons from awake guinea pigs. Arch Ital Biol 134:57-64.

Wang X, Merzenich MM, Beitel R, Schreiner CE (1995) Representation of a species-specific vocalization in the primary auditory cortex of the common marmoset: temporal and spectral characteristics. J Neurophysiol 74:2685-2706.

Yin TCT (1994) Physiological correlates of the precedence effect and summing localization in the inferior colliculus of the cat. J Neurosci 14:5170-5186.

Yost WA (2000) Fundamentals of hearing: an introduction. San Diego: Academic.

Zar JH (1984) Biostatistical analysis. Englewood Cliffs, NJ: Prentice-Hall.

Zwicker E, Fastl H (1990) Psychoacoustics: facts and models. New York: Springer. 